\title{
A POLÍTICA DA COOPERAÇÃO ESPACIAL CHINESA: CONTEXTO ESTRATÉGICOE ALCANCE INTERNACIONAL
}

\author{
Marco Cepik \\ RESUMO
}

O artigo explica as políticas de cooperação internacional da República Popular da China relacionadas às atividades no campo espacial. Em primeiro lugar, dada a estrutura de poder tripolar no sistema internacional e a dependência crescente de todos os países em relação ao espaço, explica-se que as razões chinesas para a cooperação espacial são a busca de segurança, desenvolvimento econômico e legitimidade. Em seguida, demonstra-se o estágio atual de desenvolvimento do programa espacial chinês, particularmente nos campos de satélites de imagem, navegação, comunicação e retransmissão de dados, bem como nas áreas de satélites micro e nano. Dados os incentivos estruturais, os objetivos estratégicos e o nível atual de desenvolvimento tecnológico, é possível interpretar corretamente as iniciativas multilaterais da China no contexto global, junto ao Comitê das Nações Unidas para o Uso Pacífico do Espaço Exterior (Cpous), bem como no contexto regional, com a recentemente estabelecida Organização de Cooperação Espacial da Ásia-Pacífico (Apsco). Do mesmo modo, é possível compreender o significado, potencialidade e limites práticos da cooperação bilateral chinesa com o Brasil e a África do Sul, potências regionais fora da Ásia. Conclui-se que a política de cooperação espacial chinesa visa a aumentar a influência internacional de Beijing sem gerar reações exageradas das outras grandes potências, postergando uma eventual militarização do espaço e procurando construir parcerias com potências regionais ainda incipientes no espaço, mas tendo em vista o futuro e as expectativas quanto ao impacto da digitalização.

PALAVRAS-CHAVE: cooperação espacial; Programa Espacial Chinês; segurança internacional.

\section{INTRODUÇÃO ${ }^{1}$}

As razões que levam o governo de um país a cooperar com outros governos nacionais são três: (i) a maximização dos ganhos absolutos de desenvolvimento, (ii) a minimização dos riscos relativos de segurança e (iii) o objetivo comum e solidário rumo à expansão da fronteira do conhecimento humano. Constrangimentos sistêmicos, interações estratégicas repetidas com $n$ participantes e incompletude informacional endêmica tornam o balanceamento entre os três objetivos difícil e os resultados de cada esforço cooperativo sempre incerto ${ }^{2}$.

\footnotetext{
1 Agradeço o apoio de Felipe Machado, meu assistente de pesquisa na área de Segurança Internacional na Universidade Federal do Rio Grande do Sul (Ufrgs); na pessoa dele, agradeço a toda a minha equipe de trabalho. Agradeço ainda ao Conselho Nacional de Desenvolvimento Científico e Tecnológico (CNPq) pela concessão da Bolsa de Produtividade em Pesquisa (PQ) e à Coordenação de Aperfeiçoamento de Pessoal de Nível Superior (Capes) o financiamento do Seminário onde iniciamos a discussão desse tema.

2 Para uma revisão do debate entre realistas e institucionalistas liberais acerca da cooperação internacional, ver Jervis (2003). Sobre a rationale da cooperação
}

Como parte de um grande esforço iniciado em 1956, a República Popular da China (RPC) está buscando desenvolver seu setor espacial primariamente para alcançar seus objetivos mais gerais de desenvolvimento econômico e social, agora no contexto das quatro modernizações lançadas em 1979 (HAGT, 2006). Além disso, o desenvolvimento e alocação de ativos no espaço é parte inseparável do conjunto de interações estratégicas chinesas no sistema internacional e, portanto, influenciam decisivamente a segurança internacional no século XXI. Conseqüentemente, a cooperação espacial da China também obedece a imperativos de segurança que não podem ser ignorados na análise (BLAIR \& CHEN, 2006; CHAMBERS, 2009).

Para explicar a cooperação técnica e comercial da China no setor espacial é preciso, portanto, situar o contexto político internacional no qual ela está inserida, o que será feito na seção II. Em se-

tecnológica no setor espacial, bem como suas exigências organizacionais e políticas específicas no contexto sul-sul, mas que não enfatiza os condicionantes estratégicos internacionais, ver a importante contribuição de Costa Filho (2006). 
guida, na seção III, serão descritos alguns programas do projeto espacial chinês, particularmente nos campos de imagem, navegação, comunicação, coleta de dados e satélites micro e nano. Estabelecidos o contexto e o conteúdo do programa espacial chinês, na seção IV do texto serão comentadas as iniciativas multilaterais de cooperação da China no contexto global, junto ao Comitê das Nações Unidas para o Uso Pacífico do Espaço Exterior (Cpous), bem como no contexto regional, com a recentemente estabelecida Organização de Cooperação Espacial da Ásia-Pacífico (Apsco), criada em dezembro de 2008, em Pequim, por Bangladesh, China, Irã, Mongólia, Paquistão, Peru e Tailândia. Por fim, na seção $\mathrm{V}$ discute-se a cooperação bilateral com potências regionais fora da Ásia, especificamente com o Brasil e com a África do Sul, de modo a demonstrar o alcance internacional e o fato de que as razões econômicas e de segurança da cooperação convivem com razões solidárias de desenvolvimento científico, ainda que subordinadas às primeiras e enfrentando significativos limites práticos.

\section{CONTEXTO ESTRATÉGICO E OBJETIVOS DACOOPERAÇÃO ESPACIAL}

O principal componente do contexto político internacional a informar as políticas de cooperação espacial chinesas é dado pela distribuição internacional de poder. A distribuição de poder vigente no sistema internacional desde o final da Guerra Fria pode ser caracterizada como sendo multipolar e desequilibrada (MEARSHEIMER, 2001). Vivemos, desde 1991, em um sistema tripolar com grandes assimetrias a favor dos Estados Unidos da América (EUA), em comparação com as outras duas grandes potências, uma decadente (Rússia) e a outra ascendente (China) ${ }^{3}$.

3 Segundo o Banco Mundial (2011), em 2010 o Produto Interno Bruto (PIB) dos Estados Unidos era de US\$14,6 trilhões, enquanto o da China era de US\$ 5,9 trilhões e o da Rússia, US\$ 1,5 trilhão. No mesmo ano, segundo o IISS (2011), os efetivos militares na ativa eram de 1,58 milhão nos Estados Unidos (0,94\% da População Economicamente Ativa (PEA)), 2,28 milhões na China ( $0,28 \%$ da PEA), e 1,05 milhão na Rússia (1,38\% da PEA). Ainda segundo o IISS (2011, p. 34), em 2010 os Estados Unidos possuíam 450 mísseis balísticos intercontinentais (ICBMs), 155 bombardeiros nucleares estratégicos e 14 submarinos nucleares capazes de lançar mísseis balísticos intercontinentais (SLBMs). A China possuía 66 ICBMs, 132 bombardeiros estratégicos e 3 submarinos SLBM, enquanto a Rússia, por sua vez, ainda detinha 376 ICBMs, 251 bombardeiros estratégicos e 14 submarinos SLBM.
Na tripolaridade assimétrica, a grande estratégia dos Estados Unidos, organizada em torno da idéia de renovar sua liderança em um mundo em crise e com maior difusão de poder (EUA, 2010a), tem esbarrado menos na existência de alianças internacionais contrabalançantes do que nas disputas internas em curso no país, bem como nos custos herdados da tentativa frustrada de obtenção da primazia nuclear e da construção de uma ordem internacional unipolar, a qual caracterizou sobremaneira os dois mandatos do presidente George W. Bush. Por sua vez, a atual grande estratégia chinesa, baseada no trinômio soberania, segurança e desenvolvimento (CHINA, 2011), também enfrenta disputas internas e a herança da abordagem anterior, sintetizada pela expressão ascensão pacífica (peaceful rising). Quando o mundo tomou consciência do crescimento consistente das capacidades econômicas e militares chinesas, na virada do século, muitos governos e grupos de interesse passaram a listar a China como uma ameaça potencial, enfatizando a sua ascensão e desconfiando das suas intenções pacíficas no médio prazo (BUZAN, 2010). Finalmente, é importante mencionar a recuperação das capacidades russas e a adoção de uma postura internacional muito mais assertiva desde a década de 2000. Embora sem conseguir alterar a realidade de um declínio estrutural secular e a inconstância de suas políticas externa, de segurança e defesa, a recuperação russa foi suficiente para que as outras duas grandes potências e as regiões adjacentes da antiga área soviética (sobretudo a Europa) voltassem a considerar muito seriamente a Rússia em seus cálculos estratégicos (CEPIK, AVILA \& MARTINS, 2009).

Um segundo componente importante do contexto político internacional posterior à Guerra Fria tem sido o aprofundamento dos processos de integração regional, mais ou menos institucionalizados, capitaneados por potências regionais e/ou grupos de potências regionais. Esse tem sido, até agora, o principal fator de estabilização e de construção de alternativas à lógica da balança de poder e dos dilemas de segurança associados com a ordem multipolar desequilibrada. (CHAN, 2010) ${ }^{4}$.

\footnotetext{
4 Ao longo da última década, mas particularmente após o início da crise econômica de 2008, a desigualdade relativa de riqueza e poder entre os Estados Unidos e a China diminuiu, mas não deixou de existir. Um dos resultados ainda incertos da crise mundial é o seu impacto sobre os processos de integração regional.
} 
Juntamente com a distribuição tripolar e assimétrica de poder e com os processos de integração regional, há um terceiro componente do contexto político internacional importante para explicar a política de cooperação espacial chinesa. Trata-se da chamada expansão conceitual da agenda de segurança. Inicialmente proposta de modo normativo e ambíguo para focalizar as ameaças não militares à segurança dos indivíduos, a ampliação da agenda de segurança internacional no começo do século XXI decorre, na verdade, de uma dupla pressão estrutural. Por um lado, a transição demográfica e seus impactos sobre a matriz energética mundial tornam mais críticos os requerimentos logísticos de sustentação da grande estratégia de todos os estados. Por outro lado, o avanço do processo de digitalização implica a crescente dependência de todos os países em relação ao ciberespaço e às tecnologias associadas ao espaço sideral. Petróleo, alimentos, minerais, internet e satélites são termos-chave para a criar um sentido renovado de dilemas de segurança em áreas de atividade humana diferentes das ameaças militares convencionais.

Na medida em que o espaço exterior à atmosfera terrestre passa a ser mais decisivo para a configuração da ordem internacional, a interação entre os diversos atores com interesses no espaço adquire contornos de um dilema de segurança (BLAIR \& CHEN, 2006). O poder militar é, portanto, uma parte inerente de qualquer política ou programa espacial de qualquer país, quer armamentos venham ou não a ser mobilizados no espaço no futuro. Isso não significa que a cooperação em temas espaciais seja impossível, apenas destaca que ela é difícil e deve ser considerada de maneira realista ${ }^{5}$.

Somente assim é possível compreender, por exemplo, as vicissitudes enfrentadas pela proposta encaminhada conjuntamente pelos governos da

5 O espaço exterior já era importante por razões estratégicas durante a Guerra Fria, uma vez que a dissuasão mútua dependia dele para a guiagem dos mísseis balísticos intercontinentais, bem como de sensores de imagens e sinais embarcados em satélites para a vigilância mútua. O que mudou depois de 1989 foi a crescente dependência do espaço para a realização de todas as operações militares e para a economia civil (space-enabled digital networks). Para uma discussão aprofundada sobre o significado da digitalização e do comando do espaço para o equilíbrio de poder no plano global e regional, ver Martins (2008).
Rússia e da China para a Conferência sobre Desarmamento da Organização das Nações Unidas (ONU) em 2008, chamada de versão preliminar para um Tratado sobre a Prevenção da Instalação de Armas no Espaço Exterior e do Uso ou Ameaça de Uso da Força contra Objetos no Espaço Exterior $^{6}$. Tampouco se poderá apreciar o amplo significado da nova Política Espacial dos Estados Unidos, a menos que se adote um ponto de partida realista (EUA, 2010b). Afinal, em ambos os casos constrangimentos estruturais e interações competitivas limitaram a disposição expressa pelos proponentes de cooperar e ampliar a base legal da confiança mútua internacional estabelecida pelo Tratado do Espaço Exterior, assinado em 1967 e atualmente com 98 países signatários.

As razões de segurança são, em decorrência do que foi exposto até aqui, uma parte integral da política de cooperação espacial da China, tanto direta quanto indiretamente.

Diretamente, em função da assimetria de forças convencionais e nucleares em favor dos Estados Unidos e seus aliados. Afinal, ao longo dos últimos 15 anos a correlação de forças nos estreitos de Taiwan e os planos norte-americanos de desenvolvimento de uma capacidade de defesa antimísseis balísticos e de controle militar do espaço foram um importante elemento no cálculo estratégico chinês. Tais capacidades poderiam efetivamente neutralizar a capacidade chinesa de dissuasão nuclear e levar o país a uma instável e indesejável corrida armamentista (HAGT \& DUNIN, 2009). Para os militares chineses, o espaço é o coração da corrente revolução em assuntos militares e sua importância para a Grande Estratégia chinesa vem aumentando consistentemente (SWAINE \& TELLIS, 2000; BLASKO, 2006; CORDESMAN \& KLEIBER, 2007).

Indiretamente, as razões de segurança emanam da própria maturação tecnológica, dos modelos de negócios e do volume de recursos investidos nas operações comerciais envolvendo o espaço. Em primeiro lugar, são poucos os países

6 O texto completo do "Draft Treaty on Prevention of the Placement of Weapons in Outer Space and of the Threat or Use of Force against Outer Space Objects (PPWT)”, bem como o restante da documentação da Conferência sobre Desarmamento da ONU, podem ser encontrados no sítio do Escritório das Nações Unidas em Genebra (UNOG, 2008). 
com capacidade de lançamento de satélites (Estados Unidos, Rússia, Agência Espacial Européia, China, Índia, Japão e Israel). Dado o potencial uso dual civil-militar dos veículos espaciais lançadores, um Regime de Controle da Tecnologia de Mísseis (MTCR) perpassa hoje a atividade. Ademais, segundo o IISS (2007), os custos de lançamento variavam entre 15 e 125 milhões de dólares, freqüentemente igualando ou excedendo o valor da carga (payload). Finalmente, forças armadas e agências de inteligência compram serviços e produtos em um mercado espacial em franca expansão. Durante a invasão do Iraque em
2003, por exemplo, $77 \%$ das faixas de freqüência e uma parte considerável do tempo de transponder utilizados nas comunicações das forças armadas dos Estados Unidos provinham de fornecedores privados, dentre os quais vários estrangeiros (O’HANLON, 2004).

O Gráfico 1, a seguir, indica que os ativos espaciais da China ainda são muito menores do que os da Rússia e dos Estados Unidos, sendo que este responde por $90 \%$ de todo o gasto militar com o espaço anualmente, sem falar na proporção maior de ativos (assets) de uso misto e nos mais de 300 satélites de uso civil-comercial.

\section{GRÁFICO 1-ATIVOS ESPACIAIS: ESTADOS UNIDOS, RÚSSIAE CHINA}

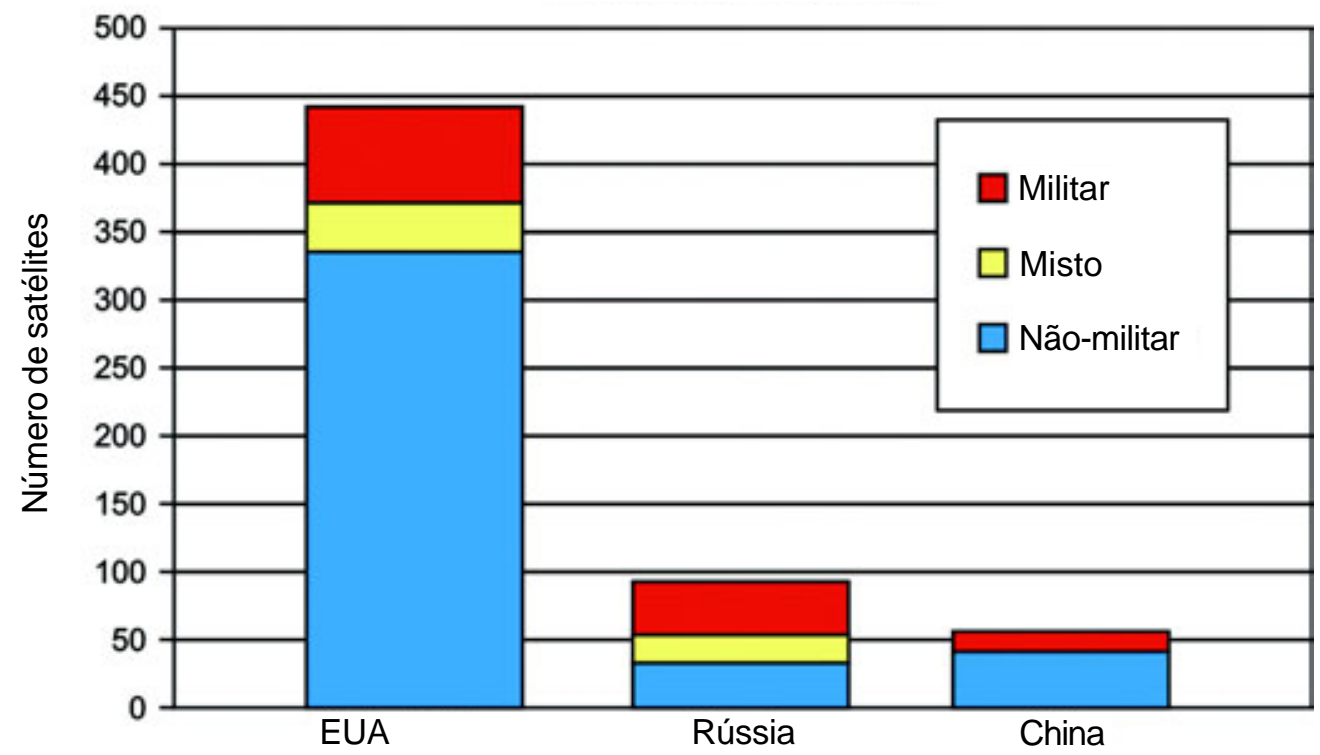

FONTE: UCS (2009).

Por sua vez, o Gráfico 2 confirma que a economia do setor espacial, embora contando com a presença da China tanto na fabricação quanto no lançamentos de satélites, ainda é firmemente dominada pelos Estados Unidos e Rússia, com a União Européia aparecendo em terceiro lugar ${ }^{7}$.

7 Para uma visão européia (francesa) acerca do contexto estratégico internacional da política espacial, ver Montluc (2009). 


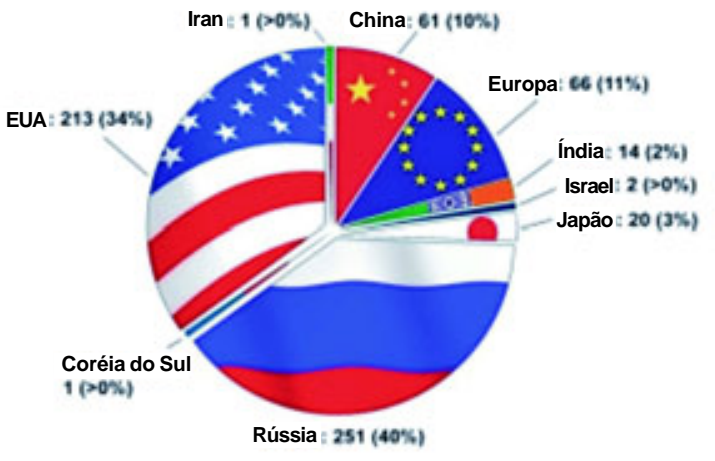

629 Successful Orbital Launches

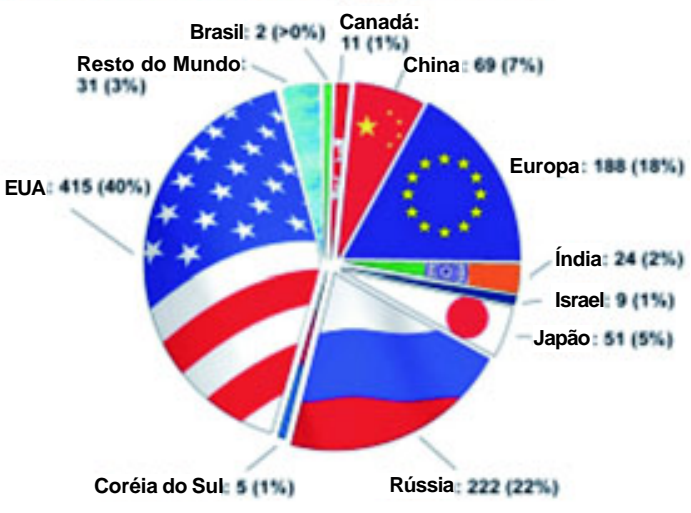

1,027 Spacecraft Manufactured

FONTE: Futron (s/d).

Ou seja, aliados estratégicos tendem a ser importantes no novo ambiente espacial, mas tais aliados serão ao mesmo tempo competidores potenciais, coetâneos ou separados por algumas décadas (HAGT, 2006, p. 91). Embora de maneira mais incerta, incipiente e com menos recursos, as potências regionais em desenvolvimento também estão desenvolvendo suas capacidades espaciais. Portanto, a cooperação técnica e comercial e as parcerias estratégicas com tais potências regionais assume um significado importante para a segurança internacional (SHEEHAN, 2007).

Mesmo considerando os demais atores, principalmente a Rússia, que coopera no setor espacial com os dois, é a interação estratégica entre Estados Unidos e China o fator singular mais importante para a evolução política e econômica do mundo no século $\mathrm{XXI}^{8}$.

Desde 1999, os EUA impuseram um embargo de facto para a exportação de tecnologias e componentes relacionados ao espaço para a China $^{9}$.

8 Reconhecer a importância da díade Estados UnidosChina não significa corroborar aqueles exageros interessados que defendem normativamente uma inexorável e acelerada militarização do espaço, decorrente de uma também “inevitável” confrontação entre os Estados Unidos e a China. Exemplos da posição sobre a "ameaça chinesa real e imediata” no espaço seriam Dolman (2002) e Seedhouse (2010).

9 Na época o Relatório da Comissão Cox, elaborado sob a demanda do Congresso Nacional dos Estados Unidos, acu-
Por mais de dez anos desde o embargo, enquanto buscava sem sucesso obter a primazia nuclear (por meio de diplomacia coercitiva, pressão econômica e guerra subterrânea) para tentar forjar uma ordem mundial unipolar, Washington evitou negociações com a China sobre os usos do espaço para além do já estabelecido pelo tratado de 1967. No contexto internacional que prevaleceu até 2010 , a China buscou contornar suas dificuldades de acesso às tecnologias espaciais norte-americanas de várias formas, inclusive por meio de parcerias com outros países, mas sempre procurando fortalecer o controle soberano e o desenvolvimento autônomo de suas capacidades (GUO, 2006).

A nova postura estratégica e espacial da Casa Branca a partir de 2010, sob o governo Obama, poderia modificar todo esse contexto ao criar condições para uma cooperação direta entre os Estados Unidos e a República Popular da China na área espacial (CHAMBERS, 2009; MOLTZ, 2011a). Ainda assim, dada a incerteza sobre a viabilidade interna da nova postura americana e dado que a construção, comercialização e a operação de ativos espaciais tem se tornado cada vez mais

sou a China de adquirir de maneira ilícita tecnologias sensíveis por meio de laços econômicos com empresas de satélites dos Estados Unidos. Do ponto de vista formal, os Estados Unidos subordinaram a exportação de satélites à Regulação Internacional de Movimentação de Armas (ITAR, na sigla em inglês), o que, na prática, limitou drasticamente o comércio direto entre os setores espaciais dos Estados Unidos e da China até hoje (KAN, 2003; HAGT, 2006). 
importante para a segurança econômica e militar da China, é razoável inferir que os chineses tentarão proteger seus interesses espaciais da mesma forma que os americanos o fazem (EUA, 2002; JOHNSON-FREESE, 2006). A própria lógica da interação estratégica torna as decisões de ambos os governos interdependentes e tem limitado, pelo menos até recentemente, o alcance da cooperação possível, conforme apontam Zhang (2006) e Moltz (2011b) ${ }^{10}$.

Em resumo, é possível inferir que a diplomacia espacial chinesa tem quatro objetivos principais. O primeiro é ajudar o país a obter a tecnologia necessária ao desenvolvimento de um programa espacial completo, civil e militar (WU, 2006). O segundo objetivo é o de construir legitimidade para as pretensões chinesas como grande potência na era digital e espacial. O terceiro objetivo chinês é evitar ou adiar uma disputa direta pelo comando do espaço com as demais grandes potências ${ }^{11}$. Finalmente, o quarto objetivo da diplomacia espacial chinesa é contribuir para ampliar a fatia de mercado controlada pelos agentes privados e estatais chineses, tendo em vista o crescimento acelerado de uma cadeia de valor estimada em mais de US\$ 150 bilhões ao ano (HENRI, 2010).

Dados o contexto e os objetivos da cooperação espacial chinesa, na próxima seção serão descritas algumas das capacidades na área de satélites do programa espacial chinês, pois isso é importante para qualquer avaliação ulterior sobre $o$ significado e os limites práticos da cooperação com o Brasil e a África do Sul.

\section{OS SATÉLITES NO PROGRAMA ESPACI- AL CHINÊS}

Iniciado em 1956, pouco tempo depois da fundação da República Popular da China, o programa espacial chinês vem destacando-se nos últimos anos por seus grandes investimentos e realizações, a despeito da crise econômica mundial ${ }^{12}$.

10 Sobre o significado do teste chinês de um míssil antisatélite (ASAT) em 2007 e os desdobramentos posteriores na relação entre Estados Unidos e China até 2010, ver Bao (2007) e também Lutes \& Hays (2011).

11 Para uma discussão inicial sobre o conceito de comando do espaço, ver o capítulo 7 do livro de Klein (2006).

12 Para uma breve introdução à história do programa espacial chinês e à organização política e administrativa do setor naquele país, ver Cheng (2011), Janes (2009) e também
Por exemplo, o projeto Shenzou colocou em órbita, em 2003, o primeiro taikonauta chinês ${ }^{13}$. Em 25 de setembro de 2008, Zhai Zhigang, tripulante da Shenzou-7, tornou-se o primeiro chinês a caminhar no espaço. Finalmente, no dia 29 de setembro de 2011 foi lançado com sucesso o módulo orbital não tripulado Tiangong-1, primeira etapa da construção de uma estação espacial própria. Planeja-se, dentro de dois anos, o início da acoplagem de naves como a Shenzou-8, Shenzou9 e Shenzou-10. Ainda que tais feitos tenham ocorrido 40 anos depois de feitos semelhantes por parte da Rússia (URSS) e dos Estados Unidos, eles indicam a determinação de um país que planeja uma missão tripulada completa para a Lua, até 2020, bem como missões não tripuladas para Marte, entre 2014 e 2033 (SHEEHAN, 2011).

Mesmo que nos últimos anos o programa tripulado chinês tenha capturado a atenção mundial, é importante lembrar que esse é apenas um dos componentes de um complexo programa espacial, que envolve ainda a construção e operação de sítios de lançamento (Jiuquan, Xichang e Taiyuan), veículos lançadores (como os foguetes Longa Marcha), satélites de vários tipos, sistemas e estações de telemetria, rastreamento e comando (TT\&C), espaçonaves (Shenzou), além do restante da cadeia produtiva associada ao espaço, que vai da produção ou aquisição de insumos até as aplicações derivadas das capacidades espaciais desenvolvidas (CHINA, 2006a).

Desde 1999, a cadeia de comando do programa espacial chinês vem aumentando seu grau de institucionalização ${ }^{14}$. A pesquisa militar, desenvolvimento, aquisição e uso de capacidades espaci-

Cordesman e Kleiber (2007). A posição oficial do Conselho de Estado da República Popular da China sobre a sua política espacial foi expressa em um White Paper publicado para marcar os 50 anos de seu programa espacial (CHINA, 2006a). Recomenda-se ainda a leitura da resenha de Chen e Hagt (2006).

13 Oficialmente chamados de 宇航員 (pinyin: yǔhángyuán), ou “pessoas que navegam no universo”, os astronautas chineses têm sido chamados pelos meios de comunicação, inclusive a agência oficial de notícias Xinhua, de taikonautas, um neologismo formado a partir da idéia chinesa de espaço (taikong) e da idéia grega de navegador ( $\pi \lambda o \eta \gamma o ́ \varsigma)$ (XINHUA, 2008).

14 Discute-se, entretanto, se as linhas de autoridade atualmente existentes entre as autoridades civis, militares e as diversas organizações envolvidas com as atividades espaciais seriam eficientes ou não em termos de troca de informa- 
ais para as forças armadas são responsabilidades do Departamento Geral de Armamento (GAD), um dos três departamentos da Comissão Militar Central (CMC) do Conselho de Estado. Esse departamento também é responsável pela construção e gestão dos sítios de lançamento. Por sua vez, a coordenação nacional do programa passou a ser feita pela Administração Espacial Nacional da China (CNSA), órgão subordinado diretamente ao Conselho de Estado ${ }^{15}$. A principal agência executora do programa espacial chinês é a Corporação de Ciência e Tecnologia Aeroespacial da China (CASC), sob controle da CNSA e voltada ao desenvolvimento de sistemas civis e militares ${ }^{16}$.

ções em tempo real e uso eficaz das capacidades espaciais. Cf. as imagens descritivas da cadeia de comando no programa espacial chinês em Hagt e Dunin (2009, p. 96-97).

15 Em inglês, China National Space Administration (ou 国家航无局 pinyin: Guójiā Hángtiānjú). Cf. CNSA (s/d). Por sua vez, a CNSA controla as duas maiores empresas estatais chinesas do setor aeroespacial, a China Aerospace Science and Technology Corporation (CASC) e a China Aerospace Science and Industry Corporation (CASIC). No caso da CASIC, trata-se da maior empresa estatal chinesa voltada para o desenvolvimento e construção de mísseis e outros sistemas de armas. Cf. CASIC (s/d).

16 Em inglês, China Aerospace Science and Technology Corporation (中国航天科技售国爷司). A estatal CASC é uma corporação gigantesca, com mais de 120 mil empregados, exercendo comando e controle direto sobre um grande número de entidades. Apenas para citar os nomes disponíveis oficialmente em inglês: (i) complexos de $\mathrm{P} \& \mathrm{D}$ e produção: China Academy of Launch Vehicle Technology (CALT); Academy of Aerospace Solid Propulsion Technology (AASPT); China Academy of Space Technology (CAST); Academy of Aerospace Liquid Propulsion Technology (AALPT); Sichuan Academy of Aerospace Technology (SAAT); Shanghai Academy of Space Flight Technology (SAST); China Academy of Aerospace Electronics Technology (CAAET); China Academy of Aerospace Aerodynamics (CAAA). (ii) empresas especializadas: China Satellite Communications Corporation; China Great Wall Industry Corporation (CGWIC); China Aerospace Engineering Consultation Center; China Centre for Resources Satellite Data and Application; Aerospace Science \& Technology France Co, Ltd; Aerospace Capital Holding Co, Ltd; China Aerospace Times Electronics Corporation; China Aerospace International Holdings, Ltd; Beijing Shenzhou Aerospace Software Technology Co, Ltd; Shenzhen Academy of Aerospace Technology; Aerospace Long-March International Trade Co, Ltd. (iii) outras unidades diretamente subordinadas à CASC: China Astronautics Standards Institute; China Astronautics Publishing House; Space Archives; Aerospace Communication Center; China Space News; Chinese Society of Astronautics; Aerospace Talent Development \& Exchange Center; Aerospace Printing Office. Ver Casc (s.d.).
Segundo Pollpeter (2011, p. 406-407), os dois principais desafios atuais para a governança do programa espacial chinês seriam a manutenção de um ritmo adequado de inovação tecnológica e a melhoria da sinergia civil-militar. O primeiro desafio tem sido enfrentado a partir de um Plano de Médio e Longo Prazo para o Desenvolvimento Científico e Tecnológico (MLP). O MLP foi projetado para fomentar o desenvolvimento endógeno de inovações e permitir um salto qualitativo da indústria de alta tecnologia na China. Também o $11^{\circ}$ Plano Quinquenal (2006-2010) reforçou a importância do programa espacial do país, o que ficou evidenciado pela confirmação do calendário do programa tripulado completo e da construção da estação orbital própria, mesmo com o veto dos Estados Unidos à participação da China no programa da Estação Espacial Internacional (CHINA, 2006b). Em relação à coordenação civil-militar, embora pouco seja conhecido sobre as transformações recentes, a literatura assume que as forças armadas chinesas estejam fortemente empenhadas em garantir que o programa espacial do país permita-lhes melhorar suas capacidades estratégicas e operacionais (space-enabled networkcentric operations) (BLASKO, 2006; 2011; TENG, 2006; IISS, 2007; TELLIS, 2007; CHAPMAN, 2008; KREPON, 2008; HAGT \& DUNIN, 2009).

Trata-se, pois, de avaliar o lugar da cooperação internacional diante do duplo desafio enfrentado pelo programa espacial chinês (inovação e sinergia civil-militar). Para tanto, no restante desta seção serão descritas sumariamente algumas categorias de satélites chineses, tais como sensoriamento remoto e reconhecimento, navegação e posicionamento, transferência de dados, além de micro e nano satélites ${ }^{17}$.

\section{II.1. Satélites de sensoriamento remoto, reconhe-} cimento e inteligência de imagens

Os primeiros satélites de reconhecimento com carga útil recuperável foram lançados pela China em 1975, sendo que desde então três famílias de satélites sucederam-se com ganhos crescentes de capacidade e desenvolvimento tecnológico.

17 As observações da próxima seção não pretendem ser conclusivas, pelo contrário. Trata-se de uma primeira aproximação bastante incompleta e superficial. Por motivos de tempo e espaço não foi possível incluir, por exemplo, satélites exclusivamente de uso militar ou mesmo os satélites metereológicos FY (Fengyun). Cf. Hagt e Dunin (2009), bem como Sinodefence (s/d). 
A primeira série foram os satélites FSW (ou返回式卫星 pinyin: Fanhui Shi Weixing), que inicialmente carregavam enormes rolos de filme fotográfico para capturar imagens. As missões dos satélites FSW duravam em torno de três dias e, após esse período, os rolos de filme eram lançados para a terra. Esse foi o programa que lançou o maior número de satélites chineses, tendo durado 29 anos (1974-2003).

O segundo projeto, chamado de Ziyuan, de satélites de sensoriamento remoto, teve início em 1986 e constituiu a primeira modalidade de cooperação sul-sul para o co-desenvolvimento de alta tecnologia. Os chineses vinham enfrentando algumas dificuldades no projeto do seu satélite de sensoriamento remoto, principalmente devido à falta de tecnologias de antenas de retransmissão (COSTA FILHO, 2006). Naquele momento, iniciou-se a aproximação do país com o Brasil, terceiro país no mundo capacitado para receber imagens dos satélites de sensoriamento Landsat e que também vinha trabalhando no desenvolvimento do seu primeiro satélite de sensoriamento remoto ${ }^{18}$.

Entretanto, os chineses resolveram não esperar somente pelo sucesso da cooperação com o Brasil. Concomitante ao co-desenvolvimento da série Cbers, os chineses desenvolviam suas novas versões de satélites de sensoriamento remoto, a série Ziyuan 2. Construídos pela Academia de Tecnologia Espacial da China (CAST), esses satélites foram desenvolvidos para oferecerem mapeamento terrestre por imagem de média reso- lução para auxiliar pesquisas sobre o solo, monitoramento ambiental, planejamento urbano, monitoramento de desastres naturais, avaliação de produtividade do solo e, segundo, especialistas, para prover imagens e localização de alvos para o setor militar (SINODEFENCE, s/d). A série Ziyuan 2 foi composta de três satélites, lançados em 2000, 2002 e 2004. Operavam a $778 \mathrm{~km}$ de altitude e eram equipados com câmeras de resolução estimada de até três metros e sensores multiespectrais infravermelho (CHENG, 2011).

A frota atual de satélites de sensoriamento remoto, reconhecimento e produção de imagens é chamada de Yaogan Weixing (蛋感卫星), ou simplesmente Yaogan. A posição oficial do governo chinês é que esses satélites são utilizados para aplicações civis em diversas áreas, como mapeamento terrestre, mitigação de desastres naturais, monitoramento de cultivos e planejamento urbano (CHINA, 2006a). Comentadores ocidentais, entretanto, assumem que as especificações técnicas conhecidas dos satélites permitem seu uso para fins de reconhecimento e produção de inteligência de imagens com resoluções úteis para o planejamento e execução de operações militares. É importante observar que a mesma série inclui satélites com sensores eletro-ópticos (que operam no espectro da luz visível para mapeamento digital) e satélites com Radares de Abertura Sintética (SAR) para obtenção de imagens de alta resolução em qualquer clima de noite ou de dia. A Tabela 1 apresenta alguns dados relativos aos satélites Yaogan Weixing, lançados entre 2006 e 2010.

TABELA 1 - SATÉLITES YAOGAN WEIXING DE SENSORIAMENTO E RECONHECIMENTO DA CHINA

\begin{tabular}{|c|c|c|c|c|c|c|}
\hline SATÉLITE & $\begin{array}{c}\text { DESIGNAÇÃO } \\
\text { MILITAR }\end{array}$ & ÓRGÃO & LANÇADO & $\begin{array}{c}\text { VEÍ́CULO } \\
\text { LANÇADOR }\end{array}$ & ORBITA & PERFIL \\
\hline $\begin{array}{l}\text { Yaogan } \\
\text { Weixing } 1\end{array}$ & JianBing 5-1 & SAST & Abr. 2006 & $C Z-4 B$ & SSO & $\begin{array}{c}\text { SAR } \\
\text { Radar Abertura } \\
\text { Sintética }\end{array}$ \\
\hline $\begin{array}{l}\text { Yaogan } \\
\text { Weixing } 2\end{array}$ & JianBing 6-1 & CAST & Mai.2007 & $C Z-2 D$ & SSO & Eletro-óptico \\
\hline $\begin{array}{l}\text { Yaogan } \\
\text { Weixing } 3\end{array}$ & JianBing $5-2$ & SAST & Nov.2007 & $C Z-4 C$ & SSO & SAR \\
\hline
\end{tabular}

18 Com o acordo assinado em 1988, os dois países engajaram-se na produção do primeiro satélite da série sensoriamento remoto, a qual previa inicialmente o lançamento em conjunto de dois artefatos. Contudo, devido uma série de imprevistos enfrentados pelos parceiros, o primei- ro satélite só foi lançado 11 anos depois da assinatura do acordo. O satélite sino-brasileiro de sensoriamento remoto (Cbers) é o nome utilizado por esta ramificação do projeto de satélites de sensoriamento da China (INPE, s/d). 


\begin{tabular}{|c|c|c|c|c|c|c|}
\hline $\begin{array}{l}\text { Yaogan } \\
\text { Weixing } 4\end{array}$ & JianBing $6-2$ & CAST & Dez.2008 & $C Z-2 D$ & SSO & Eletro-óptico \\
\hline $\begin{array}{l}\text { Yaogan } \\
\text { Weixing } 5\end{array}$ & JianBing 8-1 & CAST & Dez.2008 & $C Z-4 B$ & sSO & Eletro-óptico \\
\hline $\begin{array}{l}\text { Yaogan } \\
\text { Weixing } 6\end{array}$ & JianBing 91 & SAST & Abr. 2009 & $C Z-2 C$ & sso & SAR \\
\hline $\begin{array}{l}\text { Yaogan } \\
\text { Weixing } 7\end{array}$ & JianBing $6-3$ & CAST & Dez.2009 & $C Z-2 D$ & SSO & Eletro-óptico \\
\hline $\begin{array}{l}\text { Yaogan } \\
\text { Weixing } 8\end{array}$ & JianBing 92 & SAST & Dez.2009 & $C Z-4 C$ & SSO & SAR \\
\hline $\begin{array}{l}\text { Yaogan } \\
\text { Weixing } 9 \\
\text { A/B / C }\end{array}$ & ? & CAST & Mar.2010 & $C Z-4 C$ & sso & $\begin{array}{c}\text { Eletro-óptico } \\
\text { SAR / ELINT / } \\
\text { Utilizados em } \\
\text { formação para } \\
\text { vigilância oceânica } \\
\text { (NOSS) }\end{array}$ \\
\hline $\begin{array}{l}\text { Yaogan } \\
\text { Weixing } 10\end{array}$ & JianBing 93 & SAST & Ago.2010 & $C Z-4 C$ & SSO & SAR \\
\hline $\begin{array}{l}\text { Yaogan } \\
\text { Weixing } 11\end{array}$ & JianBing $6-4$ & CAST & Set2010 & $C Z-4 C$ & SSO & Eletro-óptico \\
\hline
\end{tabular}

FONTE: Sinodefence (s/d).

Os satélites mais recentes da série apresentam significativo avanço tecnológico em termos de vida útil, capacidade de armazenamento, velocidade e banda de transmissão de imagens em tempo real, bem como na resolução das imagens produzidas pelos radares de abertura sintética, sensores eletroópticos, infravermelho e sensores multiespectrais.

\section{II.2. Satélites de navegação e posicionamento}

A China vem desenvolvendo um projeto de navegação por satélites desde 1994. De maneira distinta do sistema russo Glonass e do estadunidense GPS, que utilizam órbitas intermediárias, a tecnologia e o conceito operacional utilizados inicialmente pelos chineses baseavam-se na emissão de sinais a partir da terra e na triangulação com satélites em órbitas geoestacionárias e, por isso, demandaram comparativamente um número pequeno de satélites (três, quando o GPS utilizava mais de 20).

Conhecido como BeiDou 北斗导航系统; pinyin: Běidǒu dǎoháng xìtǒng), o programa chinês tornou-se operacional em 2003, quando o lançamento do satélite Beidou 1C completou os dois primeiros, Beidou 1A e Beidou 1B, lançados em 2000. Um quarto satélite Beidou foi lançado em 2007.
Como demonstrou Forden (2004), o projeto Beidou constituiu um sistema de navegação regional experimental, com poucas aplicações iniciais para uso civil e comercial, mas que teria sido, após 2004, suficiente para prover serviços de boa acurácia (menos de 10 m e 100 nanossegundos) para aplicações militares, incluindo melhora significativa na precisão da guiagem dos mísseis balísticos intercontinentais chineses.

Neste sentido, pode-se dizer que o Beidou contribuiu para dissuadir os Estados Unidos da tentativa de obter a primazia nuclear na década de 2000. Segundo Tellis (2007), o conceito operacional do Beidou está sendo utilizado no projeto Indian Regional Navigational Satellite System (IRNSS), que a Índia pretende inaugurar em $2014^{19}$.

19 Para maiores detalhes sobre o veículo lançador, estações de controle, rastreamento e correção, bem como parâmetros orbitais, especificações técnicas e capacidade de uso, ver Sinodefence (s/d) e também Beidou (s/d). Sobre a função e as configurações de sistemas de melhoria de desempenho dos satélites de navegação (augmentation), ver Inside GNSS (s/d). 
Em 2004, o governo chinês aprovou a construção de um sistema global de navegação, chamado de Compass Navigation Satellite System (北斗卫星导航系繁 pinyin: Běidǒu wèixing dàoháng xìtǒng). Esse projeto CNSS também é chamado na mídia de Beidou-2, mas, na verdade, não se trata de um desenvolvimento do mesmo conceito de operações e tecnologia utilizados no Beidou1. A rede CNSS será instalada em duas etapas. A primeira, prevista para 2012, criará um sistema regional de navegação com 12 satélites, com acurácia melhor e mais serviços do que o Beidou-1 era capaz. Para a segunda etapa, prevista para ser completada até 2020, a rede Compass terá alcance glo- bal, com cinco satélites em órbita geoestacionária e 30 satélites em órbitas intermediária (MEO). Segundo Sinodefence (s/d) e também Inside GNSS (s/d), a rede Compass poderá prover serviços de posicionamento com $5 \mathrm{~m}$ de acurácia (ou $8 \mathrm{~m}$ em três dimensões) para usuários globais, além de serviços com mais segurança e resoluções ainda maiores para uso das forças armadas chinesas.

Na Tabela 2 é possível comparar os conceitos dos sistemas de navegação já em funcionamento dos Estados Unidos (GPS), da Rússia (Glonass) e da China (CNSS), bem como os projetos bastante incertos da Europa (Galileo), Índia (Irnss) e Japão (QZSS).

\section{TABELA2 - COMPARANDO SISTEMAS DE NAVEGAÇÃO E POSICIONAMENTO}

\begin{tabular}{|c|c|c|c|c|c|c|}
\hline \multirow{2}{*}{\multicolumn{7}{|c|}{$\begin{array}{l}\text { Europa } \\
\text { Positionia } \\
\text { Positing, Navaigation, and riming Systems }\end{array}$}} \\
\hline & & & & & & \\
\hline System Name(s) & $\frac{\text { Compass }}{\text { Beidou }}$ & Galleo & $\begin{array}{l}\text { Indian Regional } \\
\text { Navigation Sastlti } \\
\text { System (IRNSS) }\end{array}$ & \begin{tabular}{|l|} 
Quass-Zerith Sats-itive \\
System (QZSS)
\end{tabular} & $\begin{array}{l}\text { Global Nawigation } \\
\text { Satellite Systsm } \\
\text { (GLONASS) }\end{array}$ & $\begin{array}{l}\text { Global Positioning } \\
\text { System (GPS) }\end{array}$ \\
\hline $\begin{array}{l}\text { Minimum } \\
\text { Constellation }\end{array}$ & 30 & 30 & 7 & 3 & (plus 3 in-obit spares) & 24 \\
\hline Current Constellation & 5 & 2 & 0 & 0 & 19 & 30 \\
\hline \multirow[t]{2}{*}{ Operational Date } & 2012 & 2014 & TBD & 2013 & 1995 & 1995 \\
\hline & $2015-20$ & & & & $2012^{\circ}$ & $2014^{4}$ \\
\hline Coverage & AsiaPacific & Global & India + Regional & Japan & Global & Global \\
\hline Consumer Equipment & Gbobal & Plamed & & Plamed & Avalisble & Avoliable \\
\hline \multicolumn{7}{|c|}{ Augmentation Systems } \\
\hline System Names) & & $\begin{array}{l}\text { European } \\
\text { Geostationary } \\
\text { Navigation Ovelay } \\
\text { Service (EGNOS) }\end{array}$ & $\begin{array}{l}\text { GPS-Aided Geo } \\
\text { Augmented } \\
\text { Navigation (GAGAN) }\end{array}$ & 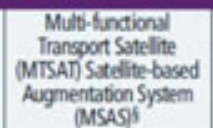 & $\begin{array}{l}\text { System of Differental } \\
\text { Correction and } \\
\text { Monitaring (SDCM) }\end{array}$ & 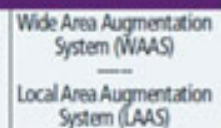 \\
\hline $\begin{array}{l}\text { Minimum } \\
\text { Constellation }\end{array}$ & & 3 & 3 & 2 & 2 & 2 \\
\hline Current Constallation & & 3 & & 2 & 0 & 2 \\
\hline Operational Date & & 2009 & 2011 & 2006 & TBD & 2003 \\
\hline Coverage & & Europe & Regional & Astroceania & Persin & North America \\
\hline
\end{tabular}

FONTE: Inside GNSS (s/d).

A Tabela 3 apresenta informações sobre os satélites Compass já lançados pela China. Em julho de 2011 foi lançado o nono satélite da rede
Compass, indicando que o cronograma previsto para a entrada em operações em 2012 está sendo cumprido. 
TABELA3 - SATÉLITES DE NAVEGAÇÃO COMPASS DA CHINA (CNSS)

\begin{tabular}{|c|c|c|c|c|}
\hline SATÉLITE & \begin{tabular}{c|} 
DATA DE \\
LANÇAMENTO \\
\end{tabular} & $\begin{array}{l}\text { CENTRO DE } \\
\text { LANÇAMENTO }\end{array}$ & $\begin{array}{l}\text { VEÍCULO } \\
\text { LANÇADOR }\end{array}$ & ÓRBITA \\
\hline Compass - M1 & Abr.2007 & Xichang & $C Z-3 A$ & MEO \\
\hline Compass-G2 & Abr.2009 & Xichang & $C Z-3 C$ & GEO - falhou \\
\hline Compass-G1 & Jan.2010 & Xichang & $C Z-3 C$ & GEO \\
\hline Compass-G3 & Jun.2010 & Xichang & $C Z-3 C$ & GEO \\
\hline $\begin{array}{l}\text { Compass - } \\
\text { IGS01 }\end{array}$ & Ago.2010 & Xichang & $C Z-3 A$ & GSO \\
\hline Compass - G4 & Set.2010 & Xichang & $C Z-3 C$ & GEO \\
\hline $\begin{array}{c}\text { Compass - } \\
\text { IGS02 }\end{array}$ & Dez.2010 & Xichang & $C Z-3 A$ & GSO \\
\hline $\begin{array}{c}\text { Compass - } \\
\text { IGSO3 }\end{array}$ & Abr.2011 & Xichang & $C Z-3 A$ & GSO \\
\hline $\begin{array}{c}\text { Compass - } \\
\text { IGS04 }\end{array}$ & Jul.2011 & Xichang & $C Z-3 A$ & GSO \\
\hline
\end{tabular}

FONTE: Sinodefence (s/d).

Assim como ocorreu com o projeto da estação orbital, paralelamente ao esforço de construir seu próprio sistema de navegação e posicionamento, a China tentou participar de programas cooperativos que lhes garantissem opções. Assim, por exemplo, em 2003 foi assinado um acordo entre Beijing e a União Européia referente à participação chinesa no projeto Galileo. As incertezas a respeito da viabilidade do projeto europeu e a excessiva dependência chinesa em relação à rede GPS dos Estados Unidos determinaram a decisão de Beijing de construir sua infraestrutura própria de posicionamento e navegação de alcance global.

\section{II.3. Satélites de comunicação}

Os satélites de comunicação foram os primeiros tipos a serem desenvolvidos pela China. O projeto foi chamado de Oriente Vermelho （东方红; pinyin: Dơngfang hóng) e lançou o primeiro satélite chinês em 1970, equipado com um transmissor de rádio e permanecendo em órbita 26 dias. Carente de linhas de comunicação que não dependessem do fornecimento externo, os chineses encararam as diversas barreiras tecnológicas que seu programa enfrentava nas primeiras décadas de sua existência e, em 1984, lançaram o Dongfanghong-2 (DFH-2). Por sua vez, o DFH-2 serviu de modelo para a série seguinte de satélites, DFH-2A, a qual, por sua vez, acabou com a dependência total da China de serviços transmissão de sinais de televisão por empresas estrangeiras, além de permitir ao país a capacidade de operacionalização de comunicações telefônicas em números razoáveis para a época. Essa série foi seguida pela DFH-3, com ca- pacidade até cinco vezes maior na promoção de serviços se comparadas com a série anterior. A produção dos DFH-3 fez-se necessária para o suporte ao desenvolvimento das telecomunicações do país e foi a primeira série de satélite lançados pelas China com o uso totalmente focado para o setor civil (CHENG, 2011) ${ }^{20}$.

O estado da arte em termos de tecnologias para satélites de comunicações chineses, no entanto, começou mudar em 2006, com o lançamento do DFH-4, o primeiro satélite de terceira geração com vida útil de 15 anos e capacidade de transmissão de sinais digitais de TV em banda larga, voz e dados (SINODEFENCE, s.d.). Essa série, que pode servir tanto para uso civil como para militar, também se insere nos planos chineses em aumentar a sua participação no mercado de satélites internacional. Devido ao seu baixo custo, os chineses têm oferecido satélites dessa terceira geração para países asiáticos, africanos e sul-americanos como alternativa às opções norte-americana, russa e européia, além de comprometer-se a construir segmentos em terra para o controle destes equipamentos e treinamento de equipes nos países interessados. $\mathrm{Na}$ Tabela 4 constam informações sobre os lançamentos de satélites de comunicação da série DFH-4.

20 Segundo o White Paper oficial do governo chinês sobre as atividades espaciais, em 2005 o governo e grandes corporações já operavam mais de 100 redes de comunicação via satélite, 34 satélites de transmissão de rádio e TV, além de uma rede de comunicação marítima via satélite de alcance global. Cf. China (2006a). 
TABELA4 - SATÉLITES DE COMUNICAÇÃO DA SÉRIE DFH-4 FABRICADOS PELA CHINA

\begin{tabular}{|c|c|c|c|}
\hline NOME & ANO & OPERADOR & SITUAÇÃO \\
\hline SINOSAT 2 & Out.2006 & Sino Sat & Abandonado devido a uma falha no painel solar \\
\hline NIGCOMSAT 1 & Mai.2007 & $\begin{array}{l}\text { Nigerian Com } \\
\text { Sat }\end{array}$ & $\begin{array}{l}\text { Falhou seis meses após o lançamento, também } \\
\text { devido a problemas no painel solar. Pevisão de } \\
\text { substituição pelo NIGCOMSAT 1R até o final de } \\
2011\end{array}$ \\
\hline VENESAT 1 & Out.2008 & $\begin{array}{l}\text { Ministério da } \\
\text { Ciência e } \\
\text { Tecnologia da } \\
\text { Venezuela }\end{array}$ & $\begin{array}{l}\text { Em operações. Primeiro satélite venezuelano, } \\
\text { chamado Simon Bolivar. }\end{array}$ \\
\hline SINOSAT 6 & Set.2010 & China Sat & Em operaçōes. Também chamado China Sat $6 \mathrm{~A}$ \\
\hline SINOSAT 5 & Jun.2011 & China Sat & Em operações. Também chamado China Sat 10 \\
\hline Pak sat $1 \mathrm{R}$ & Ago.2011 & SUPARCO & Em operações \\
\hline CHINASAT $1^{\mathrm{a}}$ & Set.2011 & PLA & $\begin{array}{l}\text { Em operações. Designação militar: Fengshuo } 2 . \\
\text { Uso para comunicaçőes digitais táticas seguras. }\end{array}$ \\
\hline
\end{tabular}

FONTE: Sinodefence (s/d).

O desenvolvimento do programa chinês de satélites de comunicação também teve, desde o início, o objetivo de garantir ao país que a comunicação entre suas linhas de defesa não fossem interrompidas em tempos de guerra. No entanto, pouco se sabe sobre as reais capacidades de comunicação através de satélites do Exército de Libertação do Povo da China (ELP), pois a maioria das informações que se tem sobre satélites de comunicação militar da China são provenientes, muitas vezes, de relatórios e de fontes do governo norte-americano (KAN, 2003).

Essas fontes estimam que o ELP disponha de satélites de comunicação distintos para uso tático e estratégico. A China teria um satélite tático, o Fenghuo-1, que teria sido lançado em 2000 e dois satélites estratégicos da série Shentong-1, tendo o primeiro sido lançado em 2003 e o outro em 2010. Ambos os satélites teriam sido desenvolvidos pela CAST e seriam versões aprimoradas da série DFH-3, operariam em órbita geoestacionária e serviriam para oferecer ao ELP linhas de comunicação e transferência de dados seguras. Um novo satélite tático, o Fengshuo-2, teria sido lançado no âmbito da série DFH-4 em setembro de 2011.

II.4. Satélites de rastreamento de satélites e retransmissão de dados

A existência do programa de desenvolvimento, produção e lançamento de satélites para rastreamento de satélites e retransmissão de dados (TDRS, ou data-relay) da China é extrema- mente recente, mas de grande relevância para o país. Isso porque satélites para a retransmissão de dados são responsáveis pelas comunicações em tempo real entre satélites em órbita e as estações em terra. Esse sistema servirá, então, para o aprimoramento das capacidades de rastreamento e telemetria de equipamentos no espaço e darão suporte, principalmente, para a instalação da estação espacial chinesa.

A responsabilidade institucional pelo desenvolvimento da primeira série chinesa de satélites datarelay é da CAST. A CAST, no entanto, ainda está no início do processo de desenvolvimento desses sistemas. Atualmente, o país possui dois satélites deste tipo, o Tianlian-1, lançado em 2008, e o Tianlian I-2, lançado de Xichang em julho de 2011, naquele que foi o vôo número 140 dos foguetes da série Longa Marcha (XINGHUA, 2011d).

\section{II.5. "Micro" e nano satélites}

O programa chinês de micro (entre 10 e 100 kg) e nano (entre 1 e $10 \mathrm{~kg}$ ) satélites, embora promissor dado o uso futuro de enormes constelações de satélites desse porte, o que decorrerá do seu baixo custo de produção e de lançamento, ainda esbarra na falta de maturidade tecnológica do país nesse campo. Tendo ciência dessas limitações, a pesquisa no campo de micro e nano satélites para operação em órbita baixa começou a ser desenvolvida sob um guarda-chuva de cooperação entre universidades chinesas e do exterior. 
O exemplo mais evidente dessa busca chinesa por parceiros para o co-desenvolvimento e transferência de tecnologia para pequenos satélites veio do programa de pesquisa encabeçado pela Universidade Tsinghua, de Beijing, e a Universidade de Surrey, no Reino Unido. A parceria entre essas duas universidades foi assinada em 1998, prevendo o treinamento e a transferência de tecnologia. Essa cooperação trouxe rápidos resultados, pois já em 2000 os chineses lançaram o micro-satélite Tsinghua-1. Outras duas instituições chinesas são também responsáveis pela pesquisa e desenvolvimento de tecnologias deste tipo de satélites, o Instituto de Microsistemas e Tecnologia da Informação de Xangai e o Instituto de Tecnologia de Harbin (HAGT, 2006).

Desde o lançamento do Tsinghua-1, a evolução desse nicho tecnológico tem recebido crescente atenção dos cientistas e dirigentes chineses. Em 2004, a China finalizou o maior parque industrial do mundo para a produção de micro e nano satélites. O parque tem uma capacidade anual de produção e teste de seis a oito satélites, bem como para o controle da aplicação de suas tecnologias. Como resultado desse volume de investimentos, a China lançou, ainda em 2004, o seu primeiro nano satélite, o Naxing-1.

Do que foi exposto até aqui, verifica-se que o programa espacial chinês é robusto e tem metas estratégicas ambiciosas. Na área de satélites, a China conta hoje com uma frota diversificada, que cobre amplo espectro de missões e funcionalidades, tendo desenvolvido competências nas áreas de pesquisa, desenvolvimento, produção, lançamento, controle e aplicações. Os desafios científicos e a inovação tecnológica na área espacial previnem qualquer difusão acelerada de capacidades e reduções drásticas de custos, mas verifica-se com a digitalização uma tendência de crescimento do número de usuários civis e militares, inclusive nos países em desenvolvimento, a qual pode contribuir para o financiamento a longo prazo dos investimentos necessários. A China já é hoje a terceira maior potência espacial global, mas, para seguir avançando, ela precisa, além de adensar seu mercado doméstico, posicionar-se como líder na Ásia-Pacífico e estabelecer sólidas parcerias com os países em desenvolvimento e as potências regionais envolvidas em processos de integração. Esse é o tema das próximas seções do trabalho.

\section{A DIMENSÃO MULTILATERAL DA COO- PERAÇÃO: CPOUS E APSCO}

Um programa espacial depende de recursos orçamentários e desenvolvimento tecnológico, mas também do esforço continuado de uma rede complexa de pessoas e instituições públicas e privadas. Para não estender o ponto sobre a relação entre a política (politics) e as políticas públicas (policies), basta dizer que a diplomacia espacial e a cooperação técnica com parceiros estratégicos têm formado parte decisiva do programa espacial chinês há décadas. Para ilustrar o argumento, nesta seção serão mencionadas brevemente duas dimensões complementares da diplomacia espacial chinesa, no âmbito global e no plano regional da ÁsiaPacífico. A próxima seção, por sua vez, traz dois casos de cooperação técnica internacional.

No âmbito global, desde 1980 a China é membro do Comitê das Nações Unidas para o Uso Pacífico do Espaço Exterior (CPOUS). Essa participação envolveu não apenas a assinatura dos tratados, acordos e convenções relativos ao espaço exterior atualmente em vigor, mas também a participação nas sessões anuais, reuniões, subcomitês de assuntos legais e técnicos, bem como a apresentação de relatórios anuais de atividades espaciais e o engajamento na agenda científica, educacional e diplomática organizada pelo Escritório das Nações Unidas para Assuntos do Espaço Exterior (Unoosa) ${ }^{21}$.

Além das atividades regulares no CPOUS, a China também têm utilizado outros fóruns da ONU e eventos comerciais e tecnológicos internacionais para divulgar (seletivamente) seus avanços no setor espacial e sustentar posições em prol de um regime formal de controle de armas no espaço. Além dos princípios, resoluções e declarações adotados pela Assembléia Geral e das votações no Conselho de Segurança, destaca-se a participação

21 Em inglês, Committee on the Peaceful Uses of Outer Space (Cpous), estabelecido pela Assembléia Geral da ONU em 1959 (resolução 1472-XIV). Inicialmente com 24 membros, o Cpous conta hoje com 70 membros. A resolução A/35/791 (de 1980) da Assembléia Geral lista a República Popular da China como membro do Cpous. O comitê é secretariado pelo Escritório das Nações Unidas para Assuntos do Espaço Exterior (United Nationas Office for Outer Space Affairs (Unoosa)), sediado em Viena. Cf. Unoosa (s/d) e, para o inteiro teor da legislação, Unoosa (2002). 
chinesa no chamado Diálogo sobre a Prevenção de Armamentos no Espaço Exterior e na Conferência para o Desarmamento.

Reiterando posições semelhantes adotadas desde 1984, o White Paper sobre Atividades Espaciais da China de 2006 orientou os representantes do país na ONU a insistirem na linha oficial de defesa do uso pacífico do espaço. Em particular, note-se a resultante proposta chinesa de resolução (apoiada pela Rússia e por mais 35 países), adotada pela Assembléia Geral da ONU em dezembro de 2007, sobre a Prevenção de uma Corrida Armamentista no Espaço (A/RES/62/20) ${ }^{22}$. Também importa mencionar novamente a proposta sino-russa de um tratado internacional banindo as armas do espaço (PPWT), apresentada na Conferência das Nações Unidas sobre Desarmamento de $2008^{23}$.

Em termos regionais, a China passou a enfatizar mais a cooperação na Ásia-Pacífico desde o décimo plano quinquenal (2001-2005), tendo reiterado essa posição no seu White Paper sobre atividades espaciais (CHINA, 2006a).

Entretanto, o início da cooperação espacial multilateral na região remonta a 1992, quando China, Paquistão e Tailândia realizaram um encontro em Beijing e impulsionaram uma iniciativa chamada Asia-Pacific Multilateral Cooperation in Space Technology and Applications (AP-MCSTA). Desde 1994, foram realizadas sete conferências do fórum, organizadas respectivamente pela Tailândia, Paquistão, Coréia do Sul, Bahrein, Irã e China. Em 2001, um secretariado permanente foi estabelecido em Beijing. Dois anos depois, em 2003, delegações oficiais de nove países da região participaram da formulação do texto de um tratado institucionalizando uma nova organização internacional, a Asia-Pacific Space Cooperation Organization (APSCO). O tratado foi assinado em 2005 na conferência de Beijing. Em setembro de

22 Resoluções com título igual ou semelhante têm sido adotadas pela Assembléia Geral da ONU desde 1981. A resolução em si é menos importante do que o protagonismo chinês e o apoio russo. Cf. o índice de resoluções da ONU sobre Espaço Exterior em UNOOSA (s/d).

23 Para a documentação completa (incluindo o resumo do Tratado PPWT) do comitê de Prevenção de uma Corrida Armamentista no Espaço (PAROS), instância formal da Conferência sobre Desarmamento, ver UNOG (s/d).
2008, 30 delegados de oito países signatários do tratado assistiram na China ao lançamento de dois satélites, respectivamente para monitoramento do meio ambiente e gerenciamento de desastres ambientais (HJ-A/B), resultados de um projeto cooperado iniciado pela AP-MCSTA em 1998, chamado de Small Multi-Mission Satellite (SMMS).

Finalmente, no dia 16 de dezembro de 2008, foi realizada a cerimônia oficial de lançamento da Apsco, da qual participaram as delegações dos sete países membros (Bangladesh, China, Irã, Mongólia, Paquistão, Peru e Tailândia), dos dois países signatários do tratado e que ainda não o ratificaram internamente (Indonésia e Turquia), além de representantes da Argentina, Malásia, Filipinas, Rússia e Sri Lanka. Indicado pelo governo chinês, Zhang Wei foi nomeado secretário-geral da organização para um mandato inicial de cinco anos. A presidência do conselho da APSCO será exercida em regime de rodízio segundo a ordem alfabética dos países membros, com mandatos de dois anos, sendo que o primeiro escolhido foi Angsumal Sunalai, da Tailândia ${ }^{24}$.

Entre 2008 e 2011, a APSCO realizou quatro reuniões do seu conselho, que passou a ser presidido pelo representante de Bangladesh em 2011. Foram definidos dez projetos prioritários e mais de 200 cientistas e técnicos receberam treinamento em instituições de outros países membros, sobretudo a China. Dentre os projetos coletivos em desenvolvimento no âmbito da APSCO, destacamse a construção de uma plataforma de serviços para compartilhamento de dados obtidos por sensoriamento remoto, além do Asia-Pacific Ground Based Optical Space Objects Observation System (APOSOS), bem como do Applied High Resolution Satellite System. A China está engajada no desenvolvimento de uma série de satélites com os países membros da APSCO, incluindo satélites pequenos e médios (500-600 kg), satélites de pesquisa, sensoriamento remoto e telecomunicações (APSCO, 2011).

24 Todas as informações foram retiradas do sítio oficial da Apsco na internet (APSCO, 2011). Para dados adicionais sobre a estrutura organizacional, projetos em curso, atividades e o texto completo da convenção, ver APSCO (2011). Embora Moltz (2011b, p. 77) afirme que a APSCO e a APMCSTA sejam inciativas complementares e que a APMCSTA continue existindo como fórum mais informal para troca de dados e treinamento, não foi possível encontrar evidências posteriores a 2008 que corroborem tal afirmação. 
De fato, a moldura institucional da Apsco permite que a China influencie diplomaticamente, compartilhe tecnologias e facilite seus negócios não apenas com os países membros, mas também com um conjunto muito mais amplo de países da Ásia e da bacia do Pacífico. Como lembrou um analista, a nova organização regional ajudou a dirimir a concepção de 'ameaça chinesa' na região, assim como ajuda a forjar ligações adicionais entre a China e os estados da região, com os quais o país geralmente buscou manter boas relações (CHENG, 2011).

Entretanto, um sinal das dificuldades de superar o dilema de segurança em relação ao espaço exterior é o fato de que, até agora, os esforços diplomáticos chineses têm sido insuficientes para ampliar a diminuta cooperação espacial com outras potências regionais importantes, notadamente o Japão, a Índia e a Coréia do Sul. Segundo Moltz (2011b), um fórum paralelo com sede em Tóquio tem sido mantido desde 1993, chamado de AsiaPacific Regional Space Agency Forum (Aprsaf). Nesse sentido, as linhas de oposição e aliança em torno da questão espacial na Ásia estariam seguindo de forma consistente os alinhamentos, rivalidades e desconfianças existentes entre as potências asiáticas a respeito de outros temas, desde a segurança energética até o impasse na península da Coréia.

Ainda assim, como advogam o próprio Moltz (2011a; 2011b) e outros, incluindo Kissinger (2011), tais dilemas não precisam e não deveriam conduzir inexoravelmente a região para uma polarização crescente. Pressões comerciais ligadas aos custos de lançamento de satélites, demandas de mercado de um número crescente de usuários de sistemas espaciais, pesquisa científica para a exploração profunda do espaço, compartilhamento de informações orbitais sobre lixo espacial (debris), monitoramento conjunto da mudança climática e respostas coordenadas à desastres naturais, todos estes são apenas alguns dos fatores e tópicos que poderiam servir de base para uma agenda multilateral mais robusta entre os dois grupos de países, juntamente com Rússia, Estados Unidos e Europa.

Na verdade, alguma coisa nesse sentido já vem sendo feita de modo muito limitado no âmbito bilateral. Apenas para citar um exemplo, o Japão e a China colaboraram ativamente para a utilização sinérgica de seus bens espaciais depois do terremoto de Sichuan, em 2008, e dos desastres natu- rais e o acidente nuclear no Japão, em 2011. No entanto, como se trata já de um tipo de cooperação bilateral, o melhor é avançar para a última parte do trabalho.

\section{A DIMENSÃO BILATERAL DA COOPERA- ÇÃO: BRASIL E ÁFRICA DO SUL}

Ainda segundo o White Paper sobre atividades espaciais (CHINA, 2006a), apenas entre 2001 e 2005 a China teria assinado 16 acordos e memorandos de entendimento com 13 países e organizações internacionais. Com o Brasil, França, Rússia e Ucrânia, foram formadas comissões conjuntas para a cooperação espacial. Embora o programa espacial chinês deva muito à experiência soviética e ainda hoje exista cooperação com a Rússia (p. ex., na missão tripulada e na espaçonave Shenzhou), o que demandaria um estudo específico, nesta seção o objetivo é analisar o significado da cooperação bilateral chinesa com o Brasil e a África do Sul, duas potências regionais fora da Ásia-Pacífico.

No caso do Brasil, a cooperação espacial é parte de uma parceria definida por ambos os países como sendo estratégica (ALTEMANI, 2004; BECARD, 2008). O que a China entende por parceria estratégica (战略炏伴关系 pinyin: zhanlue huoban guanxi) é bastante claro, pois elas "não são tratadas como alianças quasi-militares, as quais envolvem extensiva cooperação militar e de segurança, tal como pareceria implicado pelo termo “estratégico”. Antes, no léxico chinês de política externa, uma parceria é estratégica por duas razões: 1) ela é compreensiva, incluindo todos os aspectos de um relacionamento bilateral (e.g. econômico, cultural, político e de segurança); 2) ambos os países concordam em assumir compromissos bilaterais de longo prazo, avaliando os problemas de relacionamento bilateral neste contexto temporal, e, algo muito importante, não permitindo que tensões ocasionais descarrilem a parceria” (MEDEIROS, 2009, p. 82).

Considerando o fato de a China ter-se tornado, desde 2010, o principal parceiro comercial do Brasil, bem como os contenciosos potenciais associados a eventuais desequilíbrios no perfil da pauta de exportações e importações, é importante reter o significado do termo parceria estratégica. Mais especificamente no caso da cooperação espacial, embora tenham surgido dificuldades relativas à transferência de tecnologia por parte das instituições chinesas, bem como oscilações 
perturbadoras nos investimentos brasileiros para o setor, os resultados e o potencial da cooperação claramente a distinguem dos acordos comerciais que a China tem conseguido firmar a partir de uma combinação de preços mais acessíveis e esforço diplomático.

Note-se, porém, que mesmo os contratos com países em desenvolvimento e potências regionais têm sido importantes tanto para os contratantes quanto para a inserção comercial da China no mercado de satélites. Os exemplos mais citados têm sido os contratos com a Nigéria, Venezuela e Paquistão, já mencionados anteriormente em conexão com os avanços do DFH-4 na área de telecomunicações. Em 2007, foi lançado desde Xichang o satélite nigeriano NigComSat-1, o qual apresentou defeitos com menos de um ano de uso e está sendo substituído pela China's Great Wall Industry Corporation, com previsão de lançamento do novo satélite no segundo semestre de 2011 (XINHUA, 2009). Em 2008, foi construído e lançado com sucesso pelos chineses o primeiro satélite venezuelano de comunicações, o VenSat-1. Um segundo satélite venezuelano, chamado VRSS-1, também está em desenvolvimento (XINHUA, 2011b). Em agosto de 2011, a China lançou o Paksat 1-R, satélite de comunicações do Paquistão (XINHUA, 2011a). Além dos três casos mencionados, vale mencionar que a Bolívia também assinou um acordo em 2010 com a China para o lançamento de um satélite de telecomunicações. A construção do satélite, que está sendo chamado de Tupac Katari, também será feita pela China's Great Wall Industry Corporation com financiamento do Banco de Desenvolvimento da China, e o mesmo será lançado do Centro de Lançamento de Xichang em 2014 para ser operado pela Agência Espacial Boliviana (XINHUA, 2011c).
No caso do Brasil, além da cooperação bilateral com a China no setor espacial remontar a 1988, ela insere-se em um contexto de parceria estratégica e de adensamento crescente e pragmático de laços entre os dois países. Como se sabe, o primeiro acordo para o desenvolvimento de satélites de sensoriamento remoto foi assinado em julho de 1988. A parceria entre o Instituto Nacional de Pesquisas Espaciais (INPE) e a CAST previa investimentos de US\$ 300 milhões (30\% brasileiro e $70 \%$ chinês) para os dois primeiros satélites (COSTA FILHO, 2006; BECARD, 2008).

Embora a experiência com o Cbers-1 e Cbers2 tenha sido muito bem sucedida e contribuído bastante para o desenvolvimento da capacidade brasileira, as dificuldades associadas ao interregno neoliberal dos anos 1990 colocaram em dúvida o próprio programa espacial brasileiro ${ }^{25}$. Em 2002, foi assinado um acordo para a continuação do programa Cbers, com a construção de dois novos satélites (Cbers-3 e 4), com resolução de cinco metros, novas cargas úteis e uma nova divisão de investimentos de recursos entre o Brasil e a China, de 50\% para cada país (ZHAO, 2005).

Porém, em função de o lançamento do Cbers-3 ser viável apenas para um horizonte em que o Cbers2 já estivesse deixado de funcionar, com grande prejuízo para ambos os países e para os usuários do Cbers, o Brasil e a China decidiram construir o Cbers-2B, lançado em 2007 e descontinuado em 2010. O Cbers-3 tem lançamento previsto para fins de 2011, enquanto o Cbers-4 segue em ritmo normal de construção (INPE, s/d). Na Tabela 4 estão resumidos alguns dados sobre os satélites de imagens e sensoriamento remoto viabilizados pelo acordo entre Brasil e China.

TABELA 4 - SATÉLITES LANÇADOS NO ÂMBITO DA PARCERIA CHINA-BRASIL

\begin{tabular}{|c|c|c|c|c|}
\hline MISSÃO & $\begin{array}{c}\text { DATA DE } \\
\text { LANÇAMENTO }\end{array}$ & VIDA ÚTIL & APLICAÇŌES & DETALHES DE ÓRBITA \\
\hline Cbers -1 & Out.1999 & 4 anos & $\begin{array}{l}\text { Sensoriamento } \\
\text { remoto }\end{array}$ & $\begin{array}{c}\text { Tipo: Sun-synchronous } \\
\text { Altitude: } 778 \mathrm{~km} \\
\text { Periodo: } 100,26 \mathrm{~min} \\
\text { Ciclo Repetido: } 26 \text { dias }\end{array}$ \\
\hline
\end{tabular}

25 Basta lembrar que a privatização da Embratel implicou, a partir de 1998, uma dependência completa do Brasil nas órbitas geoestacionárias e a compra de todos as suas capa- cidades de comunicação via satélite de empresas privadas como a Star One (MONSERRAT FILHO, 2011). 


\begin{tabular}{|c|c|c|c|c|}
\hline Cbers-2 & Out.2003 & 5 anos & $\begin{array}{l}\text { Sensoriamento } \\
\text { remoto }\end{array}$ & $\begin{array}{l}\text { Tipo: Sun-synchronous } \\
\text { Altitude: } 778 \mathrm{~km} \\
\text { Período: } 100,26 \mathrm{~min} \\
\text { Ciclo Repetido: } 26 \text { dias }\end{array}$ \\
\hline Cbers-2B & Set.2007 & 3 anos & $\begin{array}{l}\text { Sensoriamento } \\
\text { remoto }\end{array}$ & $\begin{array}{l}\text { Tipo: Sun-synchronous } \\
\text { Altitude: } 778 \mathrm{~km} \\
\text { Periodo: } 100,26 \mathrm{~min} \\
\text { Ciclo Repetido: } 26 \text { dias }\end{array}$ \\
\hline Cbers -3 & Out.2011 (?) & 3 anos & $\begin{array}{l}\text { Sensoriamento } \\
\text { remoto }\end{array}$ & $\begin{array}{l}\text { Tipo: Sun-synchronous } \\
\text { Altitude: } 778 \mathrm{~km} \\
\text { Período: } 100,26 \mathrm{~min} \\
\text { Ciclo Repetido: } 26 \text { dias }\end{array}$ \\
\hline Cbers-4 & Out.2014 & 3 anos & $\begin{array}{l}\text { Sensoriamento } \\
\text { remoto }\end{array}$ & $\begin{array}{l}\text { Tipo: Sun-synchronous } \\
\text { Altitude: } 778 \mathrm{~km} \\
\text { Período: } 100,26 \mathrm{~min} \\
\text { Ciclo Repetido: } 26 \text { dias }\end{array}$ \\
\hline
\end{tabular}

FONTE: CEOS (2010).

Um desenvolvimento recente e que pode ter implicações para a cooperação entre Brasil e China foi o anúncio feito pelo governo brasileiro, em setembro de 2011, de que pretende lançar um satélite de comunicações em órbita geoestacionária até 2014. Integrado ao Projeto Espacial Brasileiro, o satélite tem custo previsto de US\$ 405,3 milhões. Outro satélite da mesma série deverá ser lançado em 2018. O primeiro satélite deverá atender as necessidades do Plano Nacional de Banda Larga (PNBL) e comunicações civis, reservando 20\% da capacidade para comunicações seguras das forças armadas brasileiras (MONSERRAT FILHO, 2011).

Por sua vez, a parceria bilateral entre a China e a África do Sul é mais recente e menos intensa, mas relevante para o tema geral deste artigo por duas razões. Em primeiro lugar, por causa do potencial de triangulação tendo em vista interesses comuns entre Brasil e África do Sul em diversos foros internacionais e na segurança do Atlântico Sul. Em segundo lugar, por sinalizar a possibilidade de uma ampliação ainda maior da presença chinesa na África (ALDEN, 2007).

A reentrada completa da África do Sul após o Apartheid na arena política internacional relativa ao espaço exterior deu-se apenas em 2009, com o estabelecimento de uma Política Nacional Espacial e a aprovação, ainda em 2008, de uma lei de criação da Agência Espacial Nacional da África do Sul (South African National Space Agency Act). Houve desenvolvimentos importantes durante a transição e durante o governo do Presidente Thabo Mbeki, mas a própria moldura institucional e política para o estabelecimento de parcerias interna- cionais só foi completada muito recentemente (VAN WYK, 2009; GOTTSCHALK, 2010) ${ }^{26}$.

A África do Sul mantém relações bilaterais relacionadas à ciência do espaço e tecnologias afins com potências espaciais como Estados Unidos, França, Alemanha e Reino Unido. Também mantém relações com Índia, Brasil, Cazaquistão e Rússia e, com menor intensidade, com Egito, Nigéria, Argélia, Tunísia, Quênia, Japão, Indonésia e Paraguai. Contudo, as relações mais significativas até aqui foram com a Rússia, nos marcos do acordo espacial assinado em 2005. Assim, por exemplo, em 2009, o primeiro satélite de propriedade do governo da África do Sul foi lançado por um foguete russo desde o Centro Espacial de Baikonur, Cazaquistão. O SumbandilaSAT é um

26 “O histórico de envolvimento dos sul-africanos com o espaço data de 1958, quando, utilizando equipamentos da National Aeronautics and Space Administration (NASA), foi construída uma base de rastreamento de satélites perto de Joanesburgo. Em 1961, esta estação de rastreamento foi removida para Hartebeesthoek, ao oeste de Pretória, e foi renomeada como Estação de Implementação do Espaço Profundo (Deep Space Implementation Facility). As instalações de Hartebeesthoek são atualmente conhecidas pelo nome de Conselho Pesquisa Industrial e Científica (CSIR) e Centro de Aplicações de Satélites (Satellite Applications Centre). Durante a década de 1980, o programa espacial iniciou o desenvolvimento de sistemas de foguetes de entrega e capacidades de lançamentos domésticas com principalmente aplicações militares, todavia. Terminado no início dos anos 1990, os únicos resquícios do programa espacial anterior do país são suas instalações em Western Cape, incluindo uma estação para controle de satélite perto de Bredasdorp e uma estação de integração de satélites perto de Grabouw” (VAN WYK, 2009, p. 48-49). 
satélite de pequeno porte para reconhecimento terrestre e sensoriamento remoto, com vida útil prevista para três anos a uma altura orbital de 500 $\mathrm{km}$. Ele foi desenvolvido por um consórcio liderado pela Universidade de Stellenbosch, a empresa SunSpace and Information Systems e o Conselho de Pesquisa Industrial e Científica da África do Sul (CSIR). O Centro de Aplicações de Satélites do CSIR é o responsável pelas operações, telemetria, rastreamento, controle, captura de dados e distribuição dos mesmos (VAN WYK, 2009).

Assim, por um lado, a África do Sul precisa robustecer sua diplomacia espacial para evitar o isolamento do seu projeto nacional, financiar as fases iniciais de suas operações comerciais e científicas e lidar com deseconomias de escala no futuro. No continente africano, a África do Sul tem a oportunidade de fortalecer sua diplomacia espacial por meio da Organização de Satélites de Comunicação Regional da África (Rascom), a qual já teve dois satélites lançados, o Rascom QAF-1 e Rascom QAF-1R, ambos financiados pelo governo Khadafi da Líbia (SELDING, 2010).

Por outro lado, a China pretende ampliar sua presença no setor espacial na África, a partir do contrato de mais de US\$ 300 milhões envolvendo a construção e lançamento (utilizando um foguete Longa Marcha 3-B) do satélite nigeriano de comunicações e provimento de internet banda larga. Embora a perda do NigComSat-1 em 2008 tenha levantado dúvidas sobre a continuidade da parceria com a China, o contrato foi ampliado para o lançamento de um substituto até o final de 2011. Amparada pela experiência na área de satélites de comunicação e de sensoriamento remoto, a China já manifestou seu interesse em estabelecer parcerias com o novo programa espacial nacional da África do Sul, com quem o país já assinou diversos acordos científicos e industriais em outras áreas e com quem tem cooperado em fóruns multilaterais, tais como o Cpous da ONU e, via Apsco, com a própria Rascom.

Finalmente, um desenvolvimento importantíssimo foi o acordo assinado em 2009, entre China e Brasil, para o compartilhamento de imagens e dados de sensoriamento remoto com terceiros países. Por meio da instalação de estações terrestres em diferentes países será possível a venda e a cessão de informações com cobertura em todo o continente africano. Três países já assinaram acordos com o consórcio Cbers, a saber, a própria África do Sul (CSIR), a Espanha (INTA) e o Egito (NARSS). Estações no Gabão e no Quênia (MALINDI) completariam a rede de recepção Cbers na África. Foi acordado que a China trabalhará com a estação do CSIR na África do Sul e o Brasil operaria juntamente com a Espanha a estação de Maspalomas, nas ilhas Canárias (INPE, s/d). Na Figura 1 são demonstrados os respectivos alcances das estações projetadas pela Iniciativa CBERS para a África. ${ }^{27}$

\section{FIGURA 1 - INICIATIVA CBERS PARA A ÁFRICA}

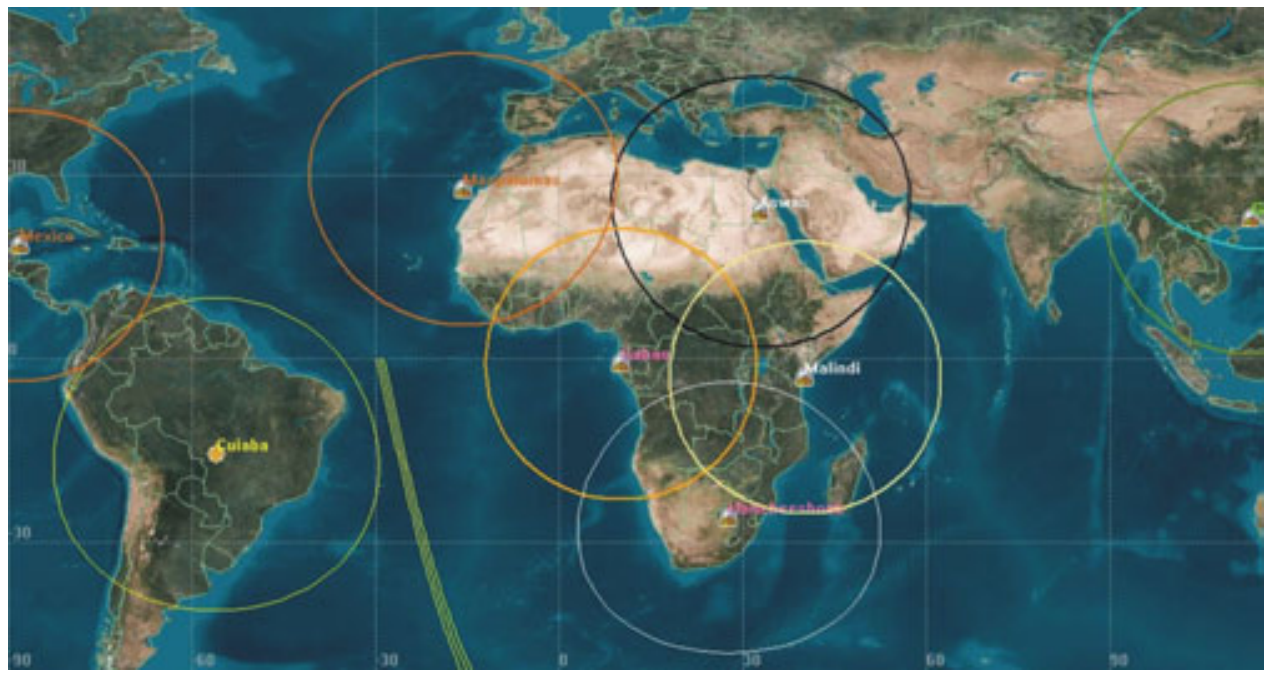

FONTE: INPE (s/d).

27 Um exemplo muito interessante das aplicações dos dados obtidos pelos satélites de imagens e sensoriamento remoto para o monitoramento e resolução de conflitos, no caso da República Democrática do Congo, foi desenvolvido há alguns anos por Van Wyk (2008). 
A diplomacia bilateral da China está em franca expansão, mesmo em relação a parceiros fora de sua região prioritária (Ásia-Pacífico) e com programas espaciais em diversos estágios de maturação e consistência estratégica. Analistas europeus e norte-americanos tendem a considerar que as motivações para estas parcerias sejam estritamente comerciais e/ou para fins de promoção da imagem da China como grande potência (CHAMBERS, 2009; MONTLUC, 2009). Na verdade, ela reflete uma visão de longo prazo do contexto internacional.

\section{CONCLUSÕES}

O contexto político da cooperação espacial da China está mudando, assim como o estágio de evolução tecnológica, institucional e operacional do programa espacial chinês.

Desde que Mao Zedong declarou, em 1958, a linha “duas bombas, um satélite”, a China passou por guerras com a Índia e com o Vietnã, por disputas militarizadas com Taiwan, Estados Unidos e a União Soviética, sobreviveu ao desastre do Grande Salto Adiante, à ruptura com a União Soviética, atravessou a Revolução Cultural Proletária, sofreu terremotos devastadores, realizou uma acidentada transição política após a morte de Mao, enfrentou as conseqüências da repressão de 1989 na Praça da Paz Celestial e viveu uma mudança profunda na sociedade e na economia em poucas décadas. A bomba atômica foi obtida em 1964, a bomba de hidrogênio em 1967 e o primeiro satélite foi lançado em 1970. Desde então, a China emergiu como a terceira potência espacial do mundo, com missões tripuladas ao espaço e mais de 70 satélites em órbita em 2011. Ainda assim, Beijing aparenta ter consciência de que ainda está bastante distante da Rússia e dos Estados Unidos (CHENG, 2011; POLLPETER, 2011).

Por ter consciência de suas limitações e ter visão de longo prazo sobre a necessidade de superálas, a política chinesa de cooperação técnica no setor espacial é parte integral da Grande Estratégia daquele país. O comando do espaço é condição necessária para a consolidação da grande potência no século XXI. Longe de ser apenas mais uma política setorial, o programa espacial chinês contribui decisivamente e subordina-se aos objetivos mais amplos daquele país em termos de maximização dos ganhos de desenvolvimento e de minimização dos riscos de segurança. Para a
China, a cooperação internacional na área espacial visa a obter conhecimentos científicos e tecnologias necessárias para a evolução de um programa espacial completo, ao mesmo tempo em que procura evitar reações contrabalanceadoras mais severas por parte dos outros dois polos mundiais de poder e seus aliados regionais. Os líderes chineses entendem, a partir de uma perspectiva clausewitziana que tem prevalecido por ora, que o exercício do comando do espaço pela presença (KLEIN, 2006, p. 62), e não necessariamente pelo uso da força, é a melhor forma de garantir o acesso continuado ao lugar mais importante para as operações militares, econômicas, políticas e sociais do século XXI.

No âmbito do comitê da ONU para o espaço exterior, a República Popular da China destaca-se por sua ênfase na denúncia da irracionalidade e das conseqüências de uma corrida espacial armada, um esforço de adiar o que se considerava até recentemente algo inevitável. Regionalmente, a criação da Apsco demonstra um novo patamar de inovação institucional para a integração, com evidente potencial econômico. Finalmente, a cooperação bilateral com potências regionais em desenvolvimento de fora da Ásia, tais como o Brasil e a África do Sul, permite algum compartilhamento de custos de desenvolvimento em segmentos específicos, mas serve principalmente para conferir alcance global para a diplomacia espacial chinesa e para necessidades operacionais futuras, decorrentes do avanço da digitalização.

Esta conclusão acerca das intenções estratégicas defensivas e das capacidades ainda relativamente limitadas da China (em comparação com Rússia e Estados Unidos) é consistente e influenciada pelas avaliações de outros autores, tais como Correll (2004), O’Hanlon (2004), Chambers (2009), Moltz (2011b) e Schmunk e Sheets (2011). Não obstante, creio que o trabalho desenvolvido aqui integra melhor os condicionantes estruturais, os objetivos estratégicos e os ritmos do desenvolvimento institucional e tecnológico do programa espacial para discernir o alcance da cooperação técnica chinesa.

O estudo do caso chinês é relevante para o Brasil porque se trata de um parceiro importante do programa espacial brasileiro, mas também porque indica que as políticas de cooperação técnica internacional das grandes potências tendem a ser mais consistentes e integradas com a grande es- 
tratégia do que se observa nas potências regionais. Isso ocorre porque o poder das grandes potências é maior, obviamente. Mas também, e isso é relevante para o Brasil, porque os custos associados ao fracasso e ao subdimensionamento de ameaças e riscos estratégicos são percebidos de maneira mais realista.
Nessa época em que o Brasil procura redimensionar sua cooperação espacial e avançar no desenvolvimento de capacidades tecnológicas centrais para a distribuição global de poder no século XXI, seria importante aprofundar o estudo comparado do contexto estratégico das políticas espaciais das grandes potências e das potências regionais.

Marco Cepik (mcepik@gmail.com) é Doutor em Ciência Política pelo Instituto Universitário de Pesquisas do Rio de Janeiro (Iuperj) e Professor de Relações Internacionais na Universidade Federal do Rio Grande do Sul (Ufrgs).

\section{REFERÊNCIAS BIBLIOGRÁFICAS}

ALDEN, C. 2007. South Africa's Space Programme: Past and Present. Strategic Review for Southern Africa. Pretoria, p. 38-51, May. Disponível em: http://findarticles.com/p/ articles/mi_hb1402/is_1_29/ai_n29365095/. Acesso em: 13.out.2011.

ALTEMANI, H. 2004. Brasil-China: trinta anos de uma parceria estratégica. Revista Brasileira de Política Internacional, Brasília, v. 47, n. 1, p. 7-30, jan.-jun. Disponível em: http:// www.scielo.br/pdf/rbpi/v47n1/v47n1a02.pdf. Acesso em: 13.out.2011.

BAO, S. 2007. Deterrence Revisited: Outer Space. China Security, Washington (DC), n. 5, p. 211, Winter. ível em: http://www.wsichina.org/ cs5_1.pdf. Acesso em: 13.out.2011.

BECARD, D. 2008. O Brasil e a República Popular da China: política externa comparada e relações bilaterais (1974-2004). Brasília: Fundação Alexandre de Gusmão.

BLAIR, B. \& CHEN, Y. 2006. Editor's Notes: The Space Security Dilemma. China Security, Washington (DC), n. 2, p. 2-15. Disponível em http://www.wsichina.org/attach/cs2_1.pdf. Acesso em: 13.out.2011.

BLASKO, D. 2006. The Chinese Army Today: Tradition and Transformation for the 21st Century. New York: Routledge.

2011. “echnology Determines Tactics”: The Relationship between Technology and Doctrine in Chinese Military Thinking. The Journal of Strategic Studies, New York, v. 34, n. 3, p. 355-381.
BUZAN, B. 2010. China in International Society: is "Peaceful Rise" Possible? Chinese Journal of International Politics, Oxford, v. 3, p. 536. Disponível em: http://www.ou.edu/ uschina/texts/Buzan.2010.CJIP.ChinaRise.pdf. Acesso em: 13.out.2011.

CEPIK, M.; AVILA, F. \& MARTINS, J. 2009. Armas estratégicas e poder no sistema internacional: o advento das armas de energia direta e seu impacto potencial sobre a Guerra e a distribuição multipolar de capacidades. Contexto Internacional, Rio de Janeiro, v. 31, n. 1, p. 49-83, jan.-abr. Disponível em: http:// www.scielo.br/pdf/cint/v31n1/02.pdf. Acesso em: 13.out.2011.

CHAMBERS, R. 2009. China's Space Program: a New Tool for PR Soft Power in International Relations? Monterey: Postgraduate School.

CHAN, S. 2010. An Odd Thing Happened on the Way to Balancing: East Asian State's reactions to China's Rise. International Studies Review, Tucson, v. 12, n. 3, p. 387-412, Sep.

CHAPMAN, B. 2008. Space Warfare and Defense: A Historical Encyclopedia and Research Guide. Santa Barbara: ABC Clio.

CHEN, Y. \& HAGT, E. 2006. Documentary Review: Shaking the Heavens. China Security, Washington (DC), n. 2, p. 116-127. Disponível em: http://www.wsichina.org/attach/ cs2_10.pdf. Acesso em: 13.out.2011.

CHENG, D. 2011. Spacepower in China. In: LUTES, C. \& HAYS, P. (eds.). Toward a Theory of Spacepower: Selected Essays. Washington 
(DC): National Defense University. Disponível em: http://www.ndu.edu/press/lib/pdf/ spacepower/spacepower.pdf. Acesso em: 13.out.2011.

CORDESMAN, A. \& KLEIBER, M. 2007. Chinese Military Modernization: Force Development and Strategic Capabilities. Washington (DC): Center for Strategic and International Studies.

CORREL, R. 2004. Military Space Cooperation: Aligning the Balance of Power and Building Common Interest. Astropolitics, New York, v. 2, n. 2, p. 133-147.

COSTA FILHO, E. 2006. A dinâmica da cooperação espacial Sul-Sul: o caso do programa Cbers (China-Brazil Earth Resources Satellite). Campinas. Tese (Doutorado em Política Científica e Tecnológica). Universidade Estadual de Campinas.

DOLMAN, E. 2002. Astropolitik: Classical Geopolitics in the Space Age. Portland: F. Cass.

FORDEN, G. 2004. The Military Capabilities and Implications of China's Indigenous SatelliteBased Navigation System. Science and Global Security, New York, n. 12, p. 219-250. Disponível em: http://web.mit.edu/stgs/pdfs/ Forden\%20 Chinese\%20Nav\%20Sats\% 20SciGlob Sec31.pdf. Acesso em: 13.out.2011.

GOTTSCHALK, K. 2010. South Africa's Space Programme: Past, Present and Future. Astropolitics, New York, v. 8, n. 1, p. 35-48. Disponível em: http://repository.uwc.ac.za/ xmlui/bitstream/handle/10566/155/ GottschalkAstropolitics 2010rev\%202011.pdf? sequence $=5$. Acesso em: 13.out.2011.

GUO, X. 2006. Blockade on China or the United States? U.S. Regulatory Policies on Space Technology Export to China. China Security, Washington (DC), n. 2, p. 73-83. Disponível em: http://www.wsichina.org/attach/cs2_7. pdf. Acesso em: 13.out.2011.

HAGT, E. 2006. Mutually Assured Vulnerabilities in Space. China Security, Washington (DC), v. 2, p. 84-106. Disponível em: http:// www.wsichina.org/attach/cs2_8.pdf. Acesso em: 13.out.2011.

HAGT, E. \& DURNIN, M. 2009. China's Antiship Ballistic Missile: Developments and Missing
Links. Naval War College Review, v. 62, n. 4, p. 87-115, Autumn.

HENRI, Y. 2010. Brief Overview of Space Market. Doha: International Telecommunication Union. Disponível em: http://www.itu.int/en/ITU-R/ space/Presentations/SpaceMarket.pdf. Acesso em: 13.out.2011.

JANES. (2009). Country Profile: China. London: Jane's Group.

JERVIS, R. 2003. Realism, Neoliberalism, and Cooperation: Understanding the Debate. In: ELMAN, C. \& ELMAN, M. F. (eds). Progress in International Relations Theory: Appraising the Field. Cambridge (MA): MIT.

JOHNSON-FREESE, J. 2006. Strategic Communication with China: What Message about Space? China Security, Washington (DC), v. 2, p. 37-57. Disponível em: http:// www.wsichina.org/attach/cs2_4.pdf. Acesso em: 13.out.2011.

KAN, S. 2003. China: Possible Missile Technology Transfers from US Satellite Export Policy Actions and Chronology. CRS Report, Congressional Research Service, Washington (DC), n. 98-48F. Disponível em: http:// www.fas.org/spp/starwars/crs/98-485.pdf. Acesso em: 13.out.2011.

KISSINGER, H. 2011. On China. New York: Penguin.

KLEIN, J. 2006. Space Warfare: Strategy, Principles and Policy. New York: Routledge.

KREPON, M. 2008. China's Military Space Strategy: an Exchange. Survival, London, v. 50, n. 1, p. 157-198. Disponível em: http:// carnegieendowment.org/files/tellis_china_ space1.pdf. Acesso em: 13.out.2011.

LUTES, C. \& HAYS, P. (eds.). Toward a Theory of Spacepower: Selected Essays. Washington (DC): National Defense University. Disponível em: http://www.ndu.edu/press/lib/pdf/ spacepower/spacepower.pdf. Acesso em: 13.out.2011.

MARTINS, J. M. 2008. Digitalização e guerra local: fatores do equilíbrio internacional. Porto Alegre. Tese (Doutorado em Ciência Política). Universidade Federal do Rio Grande do Sul. 
MEARSHEIMER, J. J. 2001. The Tragedy of Great Power Politics. New York: Norton.

MEDEIROS, E. 2009. China's International Behavior: Activism, Opportunism, and Diversification. Santa Monica: RAND.

MOLTZ, J. 2011a. The Politics of Space Security: Strategic Restraint and the Pursuit of National Interests. Palo Alto: Stanford University.

. 2011b. China, the United States, and Prospects for Asian Space Cooperation. Journal of Contemporary China, New York, v. 20 , n. 68, p $69-87$.

MONTLUC, B. 2009. The New International Political and Strategic Context for Space Policies. Space Policy, Kidlington, v. 25, n. 1, p. 20-28.

MONSERRAT FILHO, J. 2011. Satélites de comunicações serão parte do programa espacial brasileiro. AEB Notícias, 28.set. Disponível em: http://www.aeb.gov.br/indexx.php? secao=noticias\&id=743. Acesso em: 30.set.2011.

O'HANLON, M. 2004. Neither Star Wars nor Sanctuary: Constraining the Military Uses of Space. Washington (DC): Brookings.

POLLPETER, K. 2011. Upward and Onward: Technological Innovation and Organizational Change in China's Space Industry. Journal of Strategic Studies, New York, v. 34, n. 3, p. 405-423.

SCHMUNK, M. \& SHEETS, M. 2011. Challenges in the Multipolar Space-Power Environment. Seattle: CreateSpace.

SEEDHOUSE, E. 2010. The New Space Race: China vs. United States. Chichester: Springer.

SELDING, P. B. 2010. Launch Gives Africa's Rascom Consortium New Lease on Life. Space News, 5.Aug. Disponível em: http:// www.spacenews.com/satellite_telecom/ successful-launch-gives-rascom.html. Acesso em: 13.out.2011.

SHEEHAN, M. 2007. The International Politics of Space. New York: Routledge.
2011. Tiangong-1 Launch Betrays China's Earthly Ambitions. BBC News Asia-Pacific, 29.Sep. Disponível em http://www.bbc.co.uk/ news/world-asia-pacific-15089720. Acesso em: 30.set.2011.

SWAINE, M. \& TELLIS, A. 2000. Interpreting China's Grand Strategy: Past, Present and Future. Santa Monica: RAND.

TELLIS, A. 2007. China's Military Space Strategy. Survival, London, v. 49, n. 3, p. 41-72.

TENG, J. 2006. Trends in China's Space Program and the Prevention of Outer Space Weaponization. China Security, Washington (DC), n. 2, p. 65-72. Disponível em: http:// www.wsichina.org/attach/cs2_6.pdf . Acesso em: 13.out.2011.

VAN WYK, J. 2008. Space for Peace? The Use of Space Technology to Monitor Conflict Trends and Human Security in Africa. Conflict Trends (ACCORD), n. 4, p. 12-17. ível em: http://kms1.isn.ethz.ch/serviceengine/Files/ IS N/101723/ipublicationdocument_ singledocument/ccf1f66f-ce88-4a51-a0382f79df6a1b37/en/Full+Text_2008_4.pdf. Acesso em: 13.out.2011.

2009. South Africa's Space Policy and Interests: a New Dawn or a Black Hole? Strategic Review for Southern Africa, v. 31, n. 2, p. 46-73, Nov. Disponível em: http:// findarticles.com/p/articles/mi_hb1402/ is_2_31/ai_n55089501/. Acesso em: 13.out.2011.

WU, C. 2006. Development Goals of China's Space Program. China Security, Washington (DC), n. 2, p. 107-115. Disponível em: http:// www.wsichina.org/attach/cs2_9.pdf. Acesso em: 13.out.2011.

ZHANG, H. 2006. Space Weaponization and Space Security: a Chinese Perspective. China Security, Washington (DC), n. 2, p. 24-36. Disponível em: http://www.wsichina.org/ attach/CS2_3.pdf. Acesso em: 13.out.2011.

ZHAO, Y. 2005. The 2002 Space Cooperation Protocol Between China and Brazil: An Excellent Example of South-South Cooperation. Space Policy, Kidlington, v. 21, p. 213-219. 


\section{OUTRAS FONTES}

ÁFRICA DO SUL. 2009. National Space Policy.Disponível em: http://www.thedti. gov.za. Acesso em: 19.jun.2011.

APSCO. 2011. Asia-Pacific Space Cooperation Organization. Disponível em: http:// www.apsco.int/. Acesso em: 13.out.2011.

BANCO MUNDIAL. 2011. GDP data. Disponível em: http://data.worldbank.org/indicator/ NY.GDP.MKTP.CD. Acesso em: 28.set.2011.

BEIDOU. s/d. Sítio de internet. Disponível em: http://www.beidou.gov.cn. Acesso em: 13.out.2011.

CASC. s/d. China Aerospace Science and Technology Corporation. Disponível em http:/ /www.spacechina.com/english. Acesso em: 30.set.2011.

CASIC. s/d. China Aerospace Science and Industry Corporation. Disponível em: http:// www.casic.com.cn/web189296/subject/n1/ n82/n189296/index.html. Acesso em 3.out.2011.

CEOS. 2010. CEOS Database Online. Disponível em: http://database.eohandbook.com/ index.aspx. Acesso em: 18.ago.2011.

CHINA. 2002. Joint Working Paper by the Delegations of China and the Russian Federation at Conference on Disarmament in Geneva: Possible Elements for a Future International Legal Agreement on the Prevention of the Deployment of Weapons in Outer Space, the Threat or Use of Force Against Outer Space Objects. Ministry of Foreign Affairs of the People's Republic of China. Disponível em: http://www.fmprc.gov.cn/eng/wjb/zzjg/jks/ cjjk/2622/t15442.htm. Acesso em: 16.ago.2011.

2006a. White Paper: China's Space Activities in 2006. The Information Office of the State Council of the People's Republic of China. Disponível em: http://www.china. org.cn/english/features/book/183672.htm. Acesso em: 16.ago.

. 2006b. The 11th 5-Year Plan (2006-2010). Disponível em: http://www.gov.cn/english/ special/115y_index.htm. Acesso em: 18.ago.2011
2011. China's National Defense in 2010 Disponível em: http://english.gov.cn/official/ 2011-03/31/content_1835499.htm. Acesso em: 15.set.2011.

CNSA. s/d. China National Space Administration. Disponível em: http://www.cnsa.gov.cn/ n615709/cindex.html. Acesso em: 30.set.2011.

EUA. 2002. Joint Doctrine for Space Operations. Washington (DC): Joint Chiefs of Staff. Disponível em: http://www.dtic.mil/cgi-bin/ GetTRDoc?Location= U2\&doc=GetTRDoc. pdf\&AD=ADA434234. Acesso em: 2.out.2011.

2010a. National Security Strategy. Disponível em: http://www.whitehouse.gov/sites/ $\mathrm{d}$ e f a u l t / file s/rs s vi e we r/ national_security_strategy.pdf. Acesso em 30.set.2011.

2010b. National Space Policy. ível em; http://www.whitehouse.gov/sites/default/files/ national_space_policy_6-28-10.pdf. Acesso em: 30.set.2011.

FUTRON. s/d. Futron Corporation. Disponível em: http://www.futron.com. Acesso em 15.jul.

IISS. 2007. Essay: Military Space in the Era of Network-Centric Operations. The Military Balance, London, v. 104, n. 1, p. 253-260.

2011. The Military Balance, London, v. 111, n. 1.

INPE. s/d. China-Brasil Earth Resources Satellite. Disponível em: http://www.cbers.inpe.br/ ?hl=en. Acesso em: 18.ago.2011.

INSIDE GNSS. s/d. Policies, Programs, Engineering, and most Challenging Applications of the Global Navigation Satellite Systems: GPS, Galileo, GLONASS, Compass/Beidou, and Related Technologies. Disponível em: http://www.insidegnss.com. Acesso em: 30.set.2011.

SINODEFENCE. s/d. Chinese Space Program. Disponível em http://www.sinodefence.com. Acesso em: 19.ago.2011.

UCS. s/d. Satellite Database - Space Assets Chart. Disponível em: http://www.ucsusa.org/ nuclear_weapons_and_global_security/ 
space_weapons/technical_issues/ucs-satellitedatabase.html. Acesso em: 19.ago.2011.

UNOG. s.d. Disarmament Conference: Documents related to Prevention of an Arms Race in Outer Space (PAROS). Disponível em: http:// www.unog.ch/80256EE600585943/ (httpPages)/D4C4FE00A7302FB2C12575 E4002DED85?OpenDocument. Acesso em: 30.set.2011.

2008. Draft Treaty on Prevention of the Placement of Weapons in Outer Space and of the Threat or Use of Force against Outer Space Objects (PPWT). Disponível em: http:// daccess-dds-ny.un.org/doc/UNDOC/GEN/ G08/604/02/PDF/G0860402.pdf?Open Element. Acesso em: 30.set.2011.

UNOOSA. s/d. United Nations Office for Outer Space Affairs. Disponível em: www.unoosa.org. Acesso em: 27.set.2011.

UNOOSA. 2002. United Nations Treaties and Principles on Outer Space. Disponível em: http://www.oosa.unvienna.org/oosa/ index.html. Acesso em: 30.set.2011.

XINHUA. 2008. Chinese Taikonauts Return as Heroes after Landmark Spacewalk. China View, 28.set. Disponível em: http:// news.xinhuanet.com/english/2008-09/28/ content_10128407.htm. Acesso em: 13.out.2011.

2009. 因故失效的"尼星1 号"替代星将于2011

年发射升空China View, 24.mar. Disponível em: http://news.xinhuanet.com/newscenter/200903/24/content_11064713.htm. Acesso em: 13.out.2011.

2011a. China Launches Communication Satellite for Pakistan. China View, 12.ago. Disponível em: http://news.xinhuanet.com/ e n g l is h 2010 / s c i / 2011 - 08 / 12 / c_131044079.htm. Acesso em: 13.out.2011.

2011b. Venezuela Parliament Authorized New Satellite Program with China. China View, 6.maio. Disponível em: http://news. xinhuanet.com/english2010/sci/2011-05/06/ c_13861347.htm. Acesso em: 13.out.2011.

. 2011c. China, Bolivia Launch Telecom Satellite Project. China View, 10.ago. Disponível em: http://news.xinhuanet.com/ en gl is h 2010 / c h in a / 2011 - 08 / $10 /$ c_131041506.htm. Acesso em: 13.out.2011.

2011d. China Launches New Data Relay Satellite. China View, 12.jul. Disponível em: http://news.xinhuanet.com/english2010/sci/ 2011-07/12/c_13978690.htm. Acesso em: 13.out.2011. 
THE POLITICS OF CHINESE SPACE COOPERATION: STRATEGIC CONTEXT AND INTERNATIONAL SCOPE

\section{Marco Cepik}

This article explains the People’s Republic of China's policies of international cooperation for space exploration activities. In the first place, given the tri-polar power structure of the international system and the increasing dependence that all countries have on the use of outer space, we can explain Chinese motivation for spatial cooperation as unfolding from the search for security, economic development and legitimacy. Next, we demonstrate the Chinese spatial program's current state of development, with particular attention to image, navigation, communication and data transmission satellites, as well as micro and nanosatellites. Given structural incentives, strategic goals and the 
current level of technological development, we seek to provide a correct interpretation of China's multi-lateral agreements at the global level, within the context of the United Nations' Committee for Peaceful Use of Outer Space (CPOUS) and within a regional context, with the recently established Asian Pacific Space Cooperation Organization (APSCO). Similarly, we are able to understand the meaning, potential and practical limitations of Chinese bilateral cooperation with Brazil and South Africa, regional powers located outside of Asia. We conclude that Chinese space cooperation is meant to increase Beijing's international influence without generating exaggerated reactions from other major powers. Thus, China attempts to postpone the militarization of space, seeking partnerships with regional powers who are still newcomers to the field, while keeping the future and expectations linked to the impact of digitalization into account.

KEYWORDS: Space Cooperation; Chinese Space Program; International Security. 
LA POLITIQUE DE LA COOPÉRATION SPATIALE CHINOISE : LE CONTEXTE STRATÉGIQUE ET L’ATTEINTE INTERNATIONALE

\section{Marco Cepik}

L’article explique les politiques de coopération internationale de la République Populaire de la Chine, liées aux activités dans le domaine spatial. Premièrement, en ayant la structure de pouvoir tripolaire 
dans le système international et la dépendance croissante de tous les pays par rapport à l'espace, on explique que les raisons chinoises pour la coopération spatiale seraient la quête de sécurité, le développement économique et la légitimité. En suite, on révèle le stade actuel de développement du programme spatial chinois, particulièrement dans les domaines des satellites d'image, de la navigation, de la communication et de la retransmission de données, bien comme dans les domaines des satellites micro et nano. En ayant les stimulations structurelles, les objectifs stratégiques et le niveau actuel de développement technologique, il est possible d'interpréter correctement les initiatives multilatérales de la Chine dans le contexte mondial, avec le Comité des Nations Unies pour l'Utilisation Pacifique de l'Espace Extra-Atmosphérique (Copous), bien comme dans le contexte régional, avec la récente Organisation de Coopération Spatiale d'Asie-Pacifique (Apsco). De la même manière, il est possible de comprendre le significat, la potentialité et les limites pratiques de la coopération bilatérale chinoise avec le Brésil et l'Afrique du Sud, des puissances régionales hors de l’Asie. On conclut que la politique de coopération spatiale chinoise vise à augmenter l'influence internationale de Beijing sans produire des réactions excessives des autres puissances, reportant ainsi, une eventuelle militarisation de l'espace et cherchant à construire des partenariats avec des puissances régionales encore débutantes dans l'espace, mais ayant en vue l'avenir et les expectatives par rapport à l'impact de la numérisation.

MOTS-CLÉS: la coopération spatiale ; le Programme Spatial Chinois ; la sécurité internationale. 